\title{
Liver-specific LINC01146, a promising prognostic indicator, inhibits the malignant phenotype of hepatocellular carcinoma cells both in vitro and in vivo
}

Xiaoyun Ma ${ }^{1,2+}$, Meile Mo ${ }^{1 \dagger}{ }^{\dagger}$, Chao Tan ${ }^{1}$, Jennifer Hui Juan Tan ${ }^{3}$, Huishen Huang ${ }^{1}$, Bihu Liu', Dongping Huang ${ }^{4}$, Shun Liu ${ }^{5^{*}}$, Xiaoyun Zeng ${ }^{1,6^{*}}$ and Xiaoqiang Qiu ${ }^{1 *}$ (1)

\begin{abstract}
Background: Long non-coding RNAs (IncRNAs) are involved in the development of hepatocellular carcinoma (HCC). We aimed to investigate the function of LINC01146 in HCC.

Methods: The expression of LINC01146 in HCC tissues was explored via The Cancer Genome Atlas (TCGA) and Gene Expression Omnibus (GEO) databases and was verified using quantitative real-time polymerase chain reaction (qRT-PCR) in our HCC cohort. Kaplan-Meier analysis was used to assess the relationship between LINC01146 and the prognosis of HCC patients. Cell Counting Kit 8, colony formation assays, Transwell assays, flow cytometric assays, and tumour formation models in nude mice were conducted to reveal the effects of LINC01146 on HCC cells both in vitro and in vivo. Bioinformatic methods were used to explore the possible potential pathways of LINC01146 in HCC.

Results: LINC01146 was significantly decreased in HCC tissues compared with adjacent normal tissues and was found to be related to the clinical presentations of malignancy and the poor prognosis of HCC patients. Overexpression of LINC01146 inhibited the proliferation, migration, and invasion of HCC cells in vitro, while promoting their apoptosis. In contrast, downregulation of LINC01146 exerted the opposite effects on HCC cells in vitro. In addition, overexpression of LINC01146 significantly inhibited tumour growth, while downregulation of LINC01146 promoted tumour growth in vivo. Furthermore, the coexpressed genes of LINC01146 were mainly involved in the "metabolic pathway" and "complement and coagulation cascade pathway".
\end{abstract}

Conclusion: LINC01146 expression was found to be decreased in HCC tissues and associated with the prognosis of HCC patients. It may serve as a cancer suppressor and prognostic biomarker in HCC.

Keywords: Hepatocellular carcinoma, LINC01146, Prognosis, Malignant phenotype, In vitro, In vivo

*Correspondence: liushun@gxmu.edu.cn; zengxiaoyun@gxmu.edu.cn; xqqiu9999@163.com

${ }^{\dagger}$ Xiaoyun Ma and Meile Mo contributed equally to this work

${ }^{1}$ Department of Epidemiology, School of Public Health, Guangxi Medical University, Nanning, Guangxi, China

${ }^{5}$ Department of Maternal, Child and Adolescent Health, School of Public Health, Guangxi Medical University, Nanning, Guangxi, China

Full list of author information is available at the end of the article

\section{Background}

Primary liver cancer is the sixth most commonly diagnosed cancer, with an estimated 905,677 new cases and 830,180 deaths worldwide in 2020 [1]. China has the heaviest burden of primary liver cancer, with $50 \%$ of all global cases [2]. Hepatocellular carcinoma (HCC) accounts for $85-90 \%$ of primary liver cancer incidence [3]. Despite the wide scope of research on HCC diagnosis 
and treatment, approximately $60-70 \%$ of $\mathrm{HCC}$ patients have a risk of recurrence within 5 years, giving rise to poor prognosis and poor quality of life $[4,5]$. Therefore, it is urgent to discover novel prognostic biomarkers and satisfactory diagnostic and therapeutic strategies.

Long non-coding RNAs (lncRNAs) have attracted widespread attention in recent years due to their important role in HCC [6-10]. An increasing number of studies has proven that lncRNAs are associated with the proliferation, migration, invasion, apoptosis, differentiation, angiogenesis, and metabolism of HCC cell lines [11-14]. For instance, LINC00205, IncRNA RHPN1AS1, and lncRNA TMPO-AS1 directly interact with microRNAs by acting as competitive endogenous RNAs (ceRNAs) to promote the proliferation, migration, and invasion of HCC cells [15-17]. These findings are helpful in exploring the role of lncRNAs in the occurrence and metastasis of HCC and establishing a new approach for identifying lncRNAs as prognostic indicators and therapeutic targets.

In recent years, tissue-specific non-coding RNAs (ncRNAs) have shown important roles in cancer. Expression of these ncRNAs is always restricted to certain normal tissues, and they show tissue-enriched features. MiRNA122 was the first liver-specific ncRNA discovered, and it showed inhibitory effects on HCC by reducing the metastatic ability of HCC cells in vitro and tumourigenesis and angiogenesis of HCC in vivo [18]. With respect to lncRNAs, several liver-specific lncRNAs have been identified and shown cancer suppressive effects in HCC. For example, LINC01093, a novel liver-specific lncRNA, inhibits $\mathrm{HCC}$ cell proliferation and metastasis in vitro and in vivo by interacting with IGF2BP1 to promote GLI1 mRNA decay [19]. Our previous studies also showed that two novel liver-specific lncRNAs, FAM99B and LINC02499, may play similar inhibitory effects on the development of HCC [20, 21]. This evidence indicate that liver-specific lncRNAs are likely to have an important role in HCC.

LINC01146 is located on chromosome 14q31.3. Based on the quantitative RNA sequencing of major human organs and tissues from the Genotype Tissue Expression Project (GTEx) database, we found that the expression of LINC01146 in normal liver tissue was more than 3 times that in any other normal tissue, showing certain tissue specificity [22]. Based on the role of liver-specific lncRNAs in the development of HCC, we hypothesized that LINC01146 may be related to the occurrence and development of HCC. In the present study, we aimed to detect the expression level of LINC01146 in HCC tissues compared with adjacent normal tissues and investigated the exact effects of LINC01146 in vitro and in vivo. Furthermore, bioinformatic methods were used to explore the possible biological processes and potential pathways of LINC01146 in HCC and provide a scientific basis for subsequent molecular mechanism studies.

\section{Materials and methods Microarray assay}

Five pairs of HCC tissues and their corresponding adjacent normal tissues were used to conduct a highthroughput microarray expression profile by KangChen Biotech (KangChen Biotech Inc, Shanghai, China). The samples were labelled according to the ArraryStar RNA Flash Labelling Kit specifications, and Agilent SureHyb (Agilent Technologies, Palo Alto, Calif.) was used to conduct the hybridization experiments. The specific workflow is described in detail in the article by Guo X [23].

\section{The Cancer Genome Atlas (TCGA) database}

RNA sequencing data and the corresponding clinical information of $\mathrm{HCC}$ patients were obtained from the TCGA (https://cancergenome.nih.gov/) [24] database. We used RNA expression data in the transcripts per million (TPM) and converted it into the base- 2 logarithm for normalization [25]. The follow-up time and survival state of clinical information were used for Kaplan-Meier analysis. Patients without LINC01146 expression, followup time, or survival state were excluded.

\section{Gene Expression Omnibus (GEO) database}

LINC01146 expression in HCC and normal control samples was searched from the GEO (http://www.ncbi.nlm. nih.gov/geo/) [26] database. The search keywords were as follows: (long non-coding RNA OR lncRNAs) AND (hepatic OR liver OR hepatocellular) AND (cancer OR carcinoma OR tumour OR neoplasm). We also set the type to "series" and the species to "human". The inclusion criteria were as follows: (1) each chip had to contain HCC tissues and normal liver tissues; (2) the expression of LINC01146 was detected in at least three cancer tissues and normal tissues; and (3) the expression of LINC01146 data was directly available or calculable.

\section{Tissue samples}

We collected HCC tissues and adjacent normal tissues from the Affiliated Cancer Hospital of Guangxi Medical University from January 2016 to December 2019. We included patients who were about to undergo surgical excision and had not previously received additional adjuvant therapy in our HCC cohort study. The clinical features and follow-up information of patients were also collected for the survival analysis. Each patient entering our cohort signed an informed consent form. Our research was approved by the Ethics Committee of Guangxi Medical University. 


\section{HCC cell lines and animals}

In total, six HCC cell lines were used to detect the expression of LINC01146, including Huh7, Hep3B, HCCLM3, MHCC97H, SNU423, and SNU449. Dulbecco's modified Eagle's medium (DMEM), minimum essential medium (MEM), and Roswell Park Memorial Institute 1640 (RPMI-1640) (Gibco, USA) were utilized for cell culture. All $\mathrm{HCC}$ cell lines were cultured in a $37{ }^{\circ} \mathrm{C}$ incubator containing $5 \% \mathrm{CO}_{2}$.

Twenty-four specific pathogen-free (SPF) 4-week-old male nude mice $(\mathrm{BALB} / \mathrm{c})$ were housed in the Guangxi Medical University Laboratory Animal Center. The nude mice were randomly divided into 4 groups according to their weight, with 6 mice in each group. All experimental procedures were reviewed and approved by the Ethics Committee of Guangxi Medical University, and all animal experiments were performed in the Guangxi Medical University Laboratory Animal Center [SYXKGUI 20200004] in accordance with the welfare and ethical standards of animal experiments in China.

\section{Quantitative real-time polymerase chain reaction (qRT-PCR)}

Total RNA of HCC tissues and cell lines was extracted by TRIzol (Invitrogen, USA). Reverse transcription of complementary deoxyribose nucleic acid (cDNA) was conducted according to the PrimeScript RT reagent Kit (Takara, Japan). qRT-PCR was performed using the TB Green TM Premix Ex Taq TM II Kit (Takara, Japan). The primers were as follows: GAPDH forward: 5'-AGCCAC ATCGCTCAGACAC-3', GAPDH reverse: 5'-GCCCAA TACGACCAAATCC-3'; LINC01146 forward: 5'-TTG AAGGCAGTATGCTTGGTAA-3', LINC01146 reverse: 5'-TTCCGCAGTGTATCGTGTCC-3'.

\section{Cell transfection}

$\mathrm{MHCC} 97 \mathrm{H}$ and Huh7 cells were selected to construct LINC01146 stably overexpressing cell lines through lentiviral transfection, while Huh7 and Hep3B cells were selected to construct LINC01146 stably downregulated cell lines through lentiviral transfection (Genepharma, Shanghai, China). The Lv-NC and sh-NC groups served as the negative controls of the overexpression and downregulation $\mathrm{HCC}$ cell lines, respectively. After seventytwo hours of lentivirus infection, we used puromycin $(2.5$ or $3.5 \mu \mathrm{g} / \mathrm{ml})$ to screen successfully transfected HCC cells. Finally, qRT-PCR was performed to detect the efficiency of overexpression and downregulation of LINC01146 in HCC cell lines. The sequences of sh-NC and sh-LINC01146 were as follows: LINC01146-HomoNC: 5'-TTCTCCGAACGTGTCACGT-3'; LINC01146Homo-330: 5'-GGTCTCCAGCTTCGTCAATGT-3'.

\section{Cell proliferation assays}

Cell Counting Kit-8 (CCK-8; Dojindo, Japan) was used to investigate the effect of LINC01146 on the proliferation ability of HCC cells. The cells were diluted to $10^{4}$ cells/ $\mathrm{ml}$ and seeded into five 96-well plates. Then, we added a mixture of CCK-8 and complete medium (CCK-8: complete medium $=1: 10$ ) to each well after $24,48,72,96$, and $120 \mathrm{~h}$ of incubation. Finally, the absorbance value $(\mathrm{OD}=450 \mathrm{~nm})$ of each group was measured with a microplate reader after incubation for another $2 \mathrm{~h}$.

Colony formation assays were conducted to investigate the effect of LINC01146 on the proliferation ability of HCC cells. The cells were diluted to a density of 250 cells/ $\mathrm{ml}$ and cultured in a six-well plate until most clones had more than 50 cells. Afterwards, the cells were fixed with methanol and stained with $0.1 \%$ crystal violet for another $30 \mathrm{~min}$. Finally, the treated cells were scanned, and the number of clones in each group was calculated as the average number in three parallel wells.

\section{Transwell assays}

Transwell chambers with $8 \mu \mathrm{m}$ pore filters (Costar, Corning, NY) were utilized to explore the effect of LINC01146 on the migration and invasion abilities of HCC cells. The specific experimental procedure was described in our previous article [21]. The cells with serum-free medium were seeded into the upper chambers, and complete media with $20 \%$ serum was added to the lower chambers. After 48 or $72 \mathrm{~h}$, the cells were fixed with methanol and stained with $0.1 \%$ crystal violet, followed by observation and counting under an inverted microscope.

\section{Flow cytometric assays}

Flow cytometry was performed to assess the cell cycle distribution in different groups. Huh7 cells were digested and washed with PBS twice when the density of cells reached $80-90 \%$ in six-well plates. Then, the cells were fixed with cold $75 \%$ ethanol overnight at $4{ }^{\circ} \mathrm{C}$. After centrifugation, the fixed cells were washed with precooled PBS and then with periodic reagents. Afterwards, the cells were incubated with PI/RNase Staining Buffer (BD Pharmingen $^{\mathrm{TM}}$, USA) at room temperature for $15 \mathrm{~min}$, and the cycle distribution was immediately measured by flow cytometry.

To detect the apoptotic rate, the cells were digested by ethylenediaminetetraacetic acid (EDTA)-free trypsin, washed with precooled PBS and then with $1 \times$ buffer. The cells were later double stained with PE Annexin $V$ and 7-AAD according to the instructions of the PE Annexin V Apoptosis Detection Kit I (BD Pharmingen ${ }^{\mathrm{TM}}$, USA). The cell apoptosis rate was analysed by flow cytometry within $1 \mathrm{~h}$. 


\section{Tumour formation model in nude mice}

In total, $2 \times 10^{7} \mathrm{MHCC} 97 \mathrm{H}$ cells and $5 \times 10^{7} \mathrm{Huh} 7$ cells were suspended in a $2 \mathrm{ml}$ mixture $(1: 1, \mathrm{v} / \mathrm{v})$ of serumfree medium and Matrigel (Costar, Corning, NY). Then, $0.2 \mathrm{ml}$ of cell suspension was injected subcutaneously into the left axilla of the nude mice. The formed tumour was measured with a Vernier caliper every 5 days, and the tumour volume was calculated as follows: $V=1 / 2 \mathrm{ab}^{2}$, where $\mathrm{V}$ represents the volume of the tumour, while a and $b$ represent the longest and shortest diameter of the tumour, respectively. Thirty and 25 days after the inoculation of MHCC $97 \mathrm{H}$ and Huh7 cells, respectively, the nude mice were sacrificed by cervical dislocation, followed by removal, weighing, and measurement of the tumour tissues. Each tumour was then placed in $4 \%$ paraformaldehyde for fixation for $24 \mathrm{~h}$.

\section{Haematoxylin-eosin (HE) staining} and immunohistochemical (IHC) staining

For HE, after deparaffinization and rehydration, the sections were stained with haematoxylin for $8 \mathrm{~min}$ followed by 5 dips in $1 \%$ acid ethanol $(1 \% \mathrm{HCl}$ in $70 \%$ ethanol) and then rinsed in distilled water. Then, the sections were stained with $1 \%$ eosin aqueous solution for $4 \mathrm{~min}$ followed by dehydration with graded alcohol and clearing in xylene [27]. Finally, the sections were sealed with neutral adhesive and observed under a microscope.

For IHC, after incubating with antigen retrieval solution and $3 \% \mathrm{H}_{2} \mathrm{O}_{2}$ for $15-20 \mathrm{~min}$, the slides were rinsed with water and incubated with the primary antibody Ki-67 (Abcam, Cambridge, MA; 1:200) for $1 \mathrm{~h}$ at $37{ }^{\circ} \mathrm{C}$. Then, the slides were incubated with the biotinylated secondary antibody and DAB followed by haematoxylin staining [28]. Finally, the slices were dried and sealed with neutral gum. The results were analysed by ImagePro Plus 6.0 software.

\section{Coexpressed genes related to LINC01146}

GEPIA (http://gepia.cancer-pku.cn) [29], MEM (https://biit.cs.ut.ee/mem/) [30], and TANRIC (https:// ibl.mdanderson.org/tanric/_design/basic/index.html) [31] were used to predict the coexpressed genes of LINC01146. A Venn diagram (http://jvenn.toulouse. inra.fr/app/example.html) was generated to obtain the most promising coexpressed genes. Genes with at least two intersections in the Venn diagram were selected for further analysis.

\section{LINC01146 pathway analysis}

To reveal the basic molecular mechanisms of LINC01146 in HCC, we conducted a pathway enrichment analysis on the coexpressed genes of LINC01146. WebGestalt (http://www.webgestalt.org/) [32] was used to conduct Gene Ontology (GO) functional annotation, and KOBAS 3.0 (http://kobas.cbi.pku.edu.cn/kobas3) [33] was utilized to construct Kyoto Encyclopedia of Genes and Genomes (KEGG) pathway enrichment. The STRING (http:// string.embl.de/) [34] database was applied to construct a protein-protein interaction (PPI) network.

\section{Statistical analysis}

The median value was used as the cut-off value to distinguish between high- and low-expression groups, and Student's $t$ test was performed to compare the expression levels of LINC01146 in HCC tissues and normal tissues. The chi-square test was performed to explore the relationship between LINC01146 expression and the clinical features of HCC patients. Kaplan-Meier analysis and the log-rank test were used to assess the association between LINC01146 expression and the overall survival (OS) time of HCC patients. Cox regression models were utilized to explore the independent prognostic risk factors for HCC patients. The above statistical analyses were all conducted using SPSS 22.0 software, and $P<0.05$ was considered statistically significant. GraphPad Prism 8.0 was used to draw graphs.

Meta-analysis was conducted to integrate the GEO chip results using STATA 13.0 software. The chisquared and $I^{2}$ tests were used to explore the heterogeneity between studies. When $I^{2}<50 \%$ or $P>0.1$, no significant heterogeneity existed among studies, and the fixed effect model was used for meta-analysis. Otherwise, the random-effect model was selected. A forest plot was utilized to obtain the combined effect value, including the standard mean deviation (SMD) and 95\% confidence interval $(\mathrm{CI})$. When $\mathrm{SMD}<0$ and $P<0.05$, the expression of LINC01146 was considered downregulated in HCC tissues compared with adjacent normal tissues. Otherwise, the expression of LINC01146 was considered upregulated or unaltered in HCC tissues compared with adjacent normal tissues. Sensitivity analysis was used to evaluate the robustness of the meta-analysis results. The funnel graph and Egger's test were applied to evaluate reporting bias, with $P>0.1$ deemed to indicate no apparent reporting bias.

\section{Results \\ LINC01146 is downregulated based on IncRNA microarray, TCGA and GEO databases}

In our study, under the restriction of fold change (FC) $>2$ and adjusted $P<0.05$, we found 4433 differentially expressed lncRNAs in HCC, including 1708 upregulated lncRNAs and 2725 downregulated lncRNAs (GSE93789, Additional file 1: Fig. S1A). The GTEx 
database showed that LINC01146 was only expressed in a few human normal tissues and was highly expressed in normal liver tissues, which exhibited liver-specific expression characteristics (Additional file 1: Fig. S1B). Hence, we selected liver-specific LINC01146, which was downregulated in HCC tissues, as our research object $(F C=3.92, P=6.93 \mathrm{E}-4, F D R=0.027$; Additional file 2 : Table S1).

For the TCGA database, the results showed that LINC01146 was decreased in HCC tissues compared with normal liver tissues $(P<0.001$; Fig. $1 \mathrm{~A})$. In total, $330 \mathrm{HCC}$ patients with complete follow-up information were used for 5-year OS analysis. The results indicated that low LINC01146 expression was associated with poor 5 -year OS in HCC patients $(P=0.030$; Fig. 1B).

Overall, thirteen chips were involved in the metaanalysis, and detailed information is presented in Table 1. We selected the random-effect model due to heterogeneity among these studies $(P=0.007$; Fig. $1 C)$. The forest plot showed that LINC01146 was decreased in HCC tissues compared with normal liver tissues $(\mathrm{SMD}=-0.97, \quad 95 \%$ CI $[-1.33,-0.60], \quad P<0.001$; Fig. 1C). Moreover, the results showed that no reporting bias was discovered in our study $(P=0.656$; Additional file 1: Fig. S1C). The sensitivity analysis also showed that the results of this meta-analysis were stable (Additional file 1: Fig. S1D).

\section{Decreased expression of LINC01146 is associated with aggressive clinical features and poor prognosis of $\mathrm{HCC}$ patients}

The qRT-PCR results indicated that LINC01146 was downregulated in HCC tissues compared with normal tissues $(P<0.001, \mathrm{n}=88$; Fig. 1D). Furthermore, the expression of LINC01146 had a distinct negative association with tumour size $(P=0.005)$, tumour number $(P=0.020)$, microvascular invasion (MVI) $(P=0.033)$, satellite nodules $(P=0.007)$, DNA content of $\mathrm{HBV}$ $(P=0.018)$, and Barcelona Clinic Liver Cancer (BCLC) grade $(P=0.010)$, as shown in Table 2 .

The Kaplan-Meier analysis indicated that decreased LINC01146 was significantly associated with poor prognosis of HCC patients $(P<0.001, \mathrm{n}=85$; Fig. $1 \mathrm{E})$. Moreover, the multivariate Cox regression model showed that high expression of LINC01146 was an independent protective factor for the prognosis of HCC patients $(\mathrm{HR}=0.38,95 \% \mathrm{CI} 0.16-0.92, P=0.033)$, as shown in Table 3.

\section{LINC01146 inhibits the proliferation of HCC cells in vitro} The expression of LINC01146 was lowest in MHCC97H and Huh7 cells and highest in Hep3B cells by qRT-PCR
(Fig. 2A). Therefore, we chose MHCC97H and Huh7 cells to construct stable overexpressing $\mathrm{HCC}$ cell lines and Huh7 and Hep3B cells to construct stable knockdown HCC cell lines through lentiviral transfection. The results showed that LINC01146 was successfully overexpressed in MHCC97H $(P<0.001)$ and Huh7 cells $(P<0.001$; Fig. 2B) but was downregulated in Huh7 $(P<0.001)$ and Hep3B cells $(P<0.001$; Fig. 2C).

The results of CCK- 8 assays indicated that the overexpression of LINC01146 inhibited the growth rate of MHCC97H $(P<0.001$; Fig. $2 D)$ and Huh7 cells $(P<0.001$; Fig. 2E). In contrast, downregulation of LINC01146 increased the growth rate of Huh7 $(P<0.001$; Fig. $2 \mathrm{~F})$ and Hep3B cells $(P<0.001$; Fig. 2G).

In addition, colony formation assays showed that the overexpression of LINC01146 reduced the number of colonies in MHCC97H $(P<0.001)$ and Huh7 cells $(P<0.001$; Fig. $3 \mathrm{~A})$, while downregulation of LINC01146 increased the number of colonies in Huh7 $(P<0.001)$ and Hep3B cells $(P<0.001$; Fig. 3B). All of the above results showed that LINC01146 inhibits the proliferation of HCC cell lines.

\section{LINC01146 inhibits the migration and invasion abilities of HCC cell lines in vitro}

Transwell assays showed that overexpression of LINC01146 suppressed the migration $(P<0.001)$ and invasion $(P<0.001$; Fig. $4 \mathrm{~A})$ activities of MHCC97H cells, and inhibited the migration $(P<0.001)$ and invasion $(P<0.001$; Fig. 4B $)$ activities of Huh7 cells. In contrast, downregulation of LINC01146 promoted the migration $(P<0.001)$ and invasion $(P=0.001$; Fig. $4 C)$ activities of Huh7 cells, and enhanced the migration $(P=0.006)$ and invasion $(P<0.001$; Fig. 4D) activities of Hep3B cells.

\section{LINC01146 affects the cell cycle and promotes the apoptosis of $\mathrm{HCC}$ cells in vitro}

The cell cycle results showed that overexpression of LINC01146 increased the proportion of Huh7 cells in the G0/G1 phase $(64.25 \%$ vs. $54.3 \%, P<0.001)$, while reducing the proportion of cells in the $S$ phase (18.95\% vs. $24.21 \%, P<0.001$, Fig. 5A). In contrast, downregulation of LINC01146 reduced the proportion of Huh7 cells in the G0/G1 phase $(57.59 \%$ vs. $63.99 \%, P<0.001)$, while increasing the proportion of cells in the $S$ phase $(32.12 \%$ vs. $24.12 \%, P<0.001$, Fig. 5B). These results suggest that LINC01146 inhibits $\mathrm{HCC}$ cell proliferation by affecting the progression of the cell cycle.

Furthermore, we assessed the effect of LINC01146 on the apoptosis of HCC cells by flow cytometry. The results showed that overexpression of LINC01146 increased the apoptotic rates of Huh7 cells $(P<0.001$, Fig. $5 C)$, while 
A

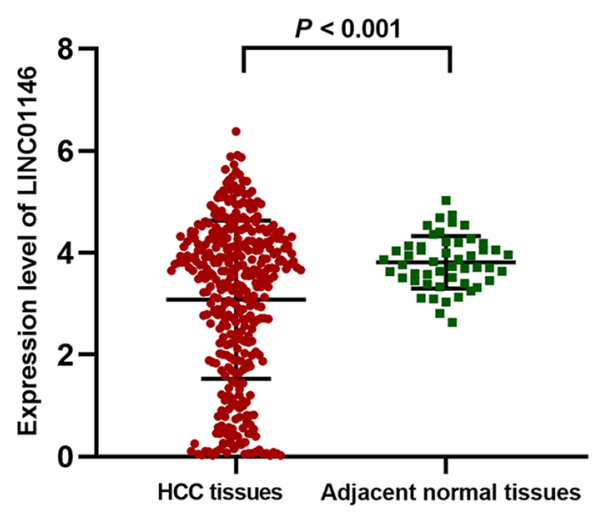

B

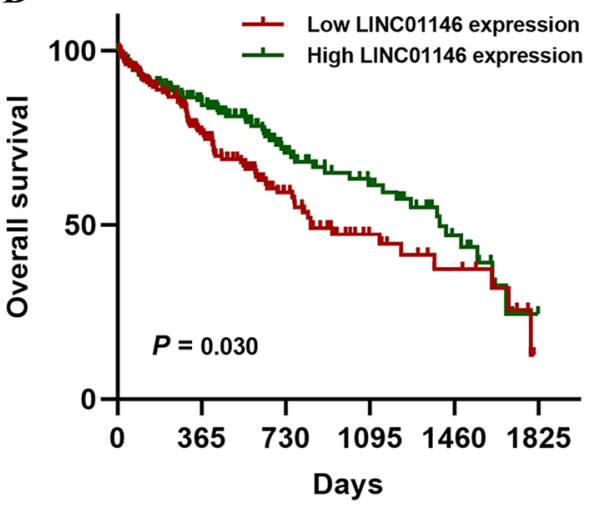

C Study

$\%$

ID

Effect $(95 \% \mathrm{CI}) \quad$ Weight

GSE29721 (2011)

GSE33006 (2011)

GSE62232 (2014)

GSE84402 (2017)

GSE93789 (2017)

GSE94660 (2017)

GSE98269 (2017)

GSE101685 (2017)

GSE101728 (2017)

GSE104310 (2017)

GSE115018 (2018)

GSE121248 (2018)

GSE124535 (2019)

Overall, DL $\left(\mathrm{I}^{2}=55.9 \%, \mathrm{p}=0.007\right)$

$-1.01(-1.95,-0.07)$

7.91

$3.26(0.49,6.04) \quad 1.59$

$-0.58(-1.49,0.33) \quad 8.17$

$-0.98(-1.77,-0.19) \quad 9.31$

$-2.16(-3.79,-0.53) \quad 3.88$

$-0.91(-1.55,-0.27) \quad 10.92$

$-3.06(-5.72,-0.40) \quad 1.71$

$-1.02(-1.86,-0.18) \quad 8.78$

$-1.90(-3.19,-0.60) \quad 5.40$

$-1.02(-1.97,-0.06) \quad 7.76$

$-1.19(-2.06,-0.32) \quad 8.47$

$-1.23(-1.67,-0.80) \quad 13.27$

$-0.22(-0.69,0.25) \quad 12.84$

$-0.97(-1.33,-0.60) \quad 100.00$

\begin{tabular}{c|cc}
\hline & & \\
\hline-5 & 0 & 5
\end{tabular}

NOTE: Weights are from random-effects model

D

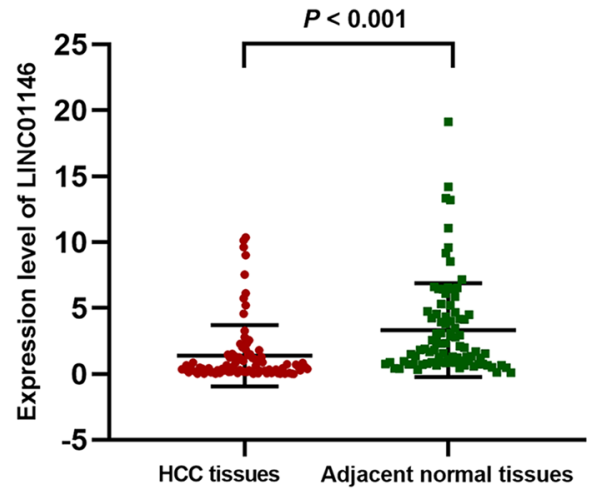

$\mathbf{E}$

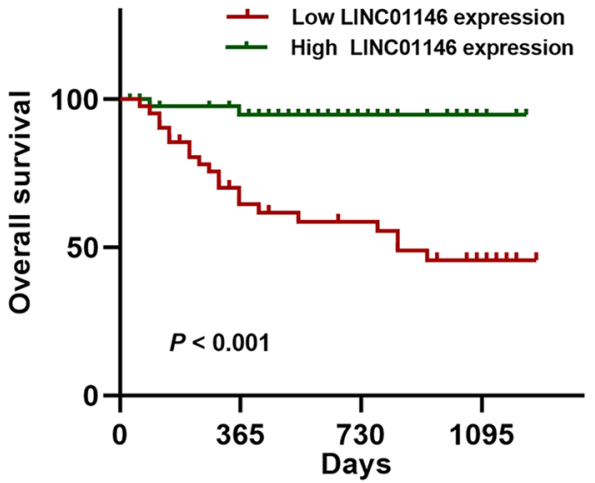

Fig. 1 The expression level of LINC01146 in HCC tissues. A LINC01146 was downregulated in HCC tissues based on the TCGA database. B The expression of LINC01146 was associated with the 5-year overall survival of HCC patients based on the TCGA database. C LINC01146 was decreased in HCC tissues based on GEO datasets (with the random-effect model). D LINC01146 was downregulated in HCC tissues from Guangxi HCC patients $(\mathrm{n}=88)$. E Low expression of LINC01146 was associated with poor overall survival in Guangxi HCC patients $(\mathrm{n}=85)$ 
Table 1 The basic information and expression of LINC01146 in the GEO datasets included in this study

\begin{tabular}{|c|c|c|c|c|c|c|c|c|}
\hline GEO datasets & Year & Platform & Country & Tissue types & $N$ & $\begin{array}{l}\text { LINC01146 } \\
\text { expression }(X \pm s)\end{array}$ & $t$ & $P$ value \\
\hline \multirow[t]{2}{*}{ GSE29721 } & 2011 & GPL570 & Canada & HCC tissue & 10 & $3.85 \pm 1.42$ & 2.21 & 0.054 \\
\hline & & & & Normal tissue & 10 & $4.88 \pm 0.24$ & & \\
\hline \multirow[t]{2}{*}{ GSE33006 } & 2011 & GPL570 & China & HCC tissue & 3 & $8.51 \pm 0.14$ & 3.70 & 0.066 \\
\hline & & & & Normal tissue & 3 & $7.51 \pm 0.41$ & & \\
\hline \multirow[t]{2}{*}{ GSE62232 } & 2014 & GPL570 & France & HCC tissue & 81 & $1.39 \pm 0.37$ & 2.90 & 0.020 \\
\hline & & & & Normal tissue & 5 & $1.60 \pm 0.14$ & & \\
\hline \multirow[t]{2}{*}{ GSE84402 } & 2017 & GPL570 & China & HCC tissue & 14 & $1.17 \pm 0.47$ & 2.78 & 0.016 \\
\hline & & & & Normal tissue & 14 & $1.53 \pm 0.22$ & & \\
\hline \multirow[t]{2}{*}{ GSE93789 } & 2017 & GPL16956 & China & HCC tissue & 5 & $4.69 \pm 2.65$ & 6.86 & $<0.001$ \\
\hline & & & & Normal tissue & 5 & $8.77 \pm 0.37$ & & \\
\hline \multirow[t]{2}{*}{ GSE94660 } & 2017 & GPL16791 & USA & HCC tissue & 21 & $1.96 \pm 1.08$ & 3.10 & 0.003 \\
\hline & & & & Normal tissue & 21 & $2.69 \pm 0.34$ & & \\
\hline \multirow[t]{2}{*}{ GSE98269 } & 2017 & GPL20712 & China & HCC tissue & 3 & $7.12 \pm 0.56$ & 3.70 & 0.066 \\
\hline & & & & Normal tissue & 3 & $8.37 \pm 0.14$ & & \\
\hline \multirow[t]{2}{*}{ GSE101685 } & 2017 & GPL570 & China & HCC tissue & 24 & $4.75 \pm 1.12$ & 2.51 & 0.018 \\
\hline & & & & Normal tissue & 8 & $5.77 \pm 0.38$ & & \\
\hline \multirow[t]{2}{*}{ GSE101728 } & 2017 & GPL21047 & China & HCC tissue & 7 & $7.92 \pm 0.94$ & 3.33 & 0.016 \\
\hline & & & & Normal tissue & 7 & $9.24 \pm 0.29$ & & \\
\hline \multirow[t]{2}{*}{ GSE104310 } & 2017 & GPL16791 & China & HCC tissue & 12 & $5.88 \pm 3.42$ & 2.23 & 0.038 \\
\hline & & & & Normal tissue & 8 & $9.09 \pm 2.68$ & & \\
\hline \multirow[t]{2}{*}{ GSE115018 } & 2018 & GPL20115 & China & HCC tissue & 12 & $1.87 \pm 1.74$ & 3.12 & 0.010 \\
\hline & & & & Normal tissue & 12 & $3.41 \pm 0.57$ & & \\
\hline \multirow[t]{2}{*}{ GSE121248 } & 2018 & GPL570 & Singapore & HCC tissue & 70 & $5.74 \pm 1.08$ & 7.49 & $<0.001$ \\
\hline & & & & Normal tissue & 37 & $6.87 \pm 0.46$ & & \\
\hline \multirow[t]{2}{*}{ GSE124535 } & 2019 & GPL20795 & China & HCC tissue & 35 & $3.97 \pm 1.75$ & 0.95 & 0.350 \\
\hline & & & & Normal tissue & 35 & $4.26 \pm 0.62$ & & \\
\hline
\end{tabular}

downregulation of LINC01146 inhibited the apoptotic rates of Huh7 cells $(P<0.001$, Fig. 5D).

\section{LINC01146 inhibits the tumour growth of $\mathrm{HCC}$ cells in vivo}

The tumour formation model in nude mice was used to evaluate the effect of LINC01146 on the proliferation of HCC cells in vivo (Fig. 6A, B). The results showed that the weight $(P=0.001$, Fig. $6 \mathrm{C})$ and volume $(P<0.001$, Fig. 6D) of tumours were significantly smaller in the overexpressed group, while tumours (weight: $P=0.001$, Fig. 6E; volume: $P<0.001$, Fig. $6 \mathrm{~F}$ ) were significantly larger in the downregulated group than in the control group.

HE staining was used to detect the effect of LINC01146 on the morphology and structure of HCC.
As shown in Fig. 7A (HE), the tumour cells in the LINC01146 downregulation group were irregular in morphology and different in nuclear size and shape, with obvious atypia, deep staining, shrinkage of nuclear membrane, active mitosis, and pathological mitosis compared with the control group.

IHC staining was used to compare the expression levels of the cell proliferation marker protein $\mathrm{Ki}-67$ between the LINC01146 downregulation group and the control group. The results showed that Ki-67 expression was significantly higher in the LINC01146 downregulation group than in the control group $(P<0.001$; Figs. 7A (IHC), B), which further indicates that downregulation of LINC01146 promotes the growth of HCC cells in vivo. 
Table 2 The relationship between LINC01146 expression and clinical features of HCC patients

\begin{tabular}{|c|c|c|c|c|c|}
\hline \multirow[t]{2}{*}{ Characteristics } & \multirow{2}{*}{$\begin{array}{l}\text { Number } \\
(\mathrm{n}=\mathbf{8 8})\end{array}$} & \multicolumn{2}{|c|}{ LINC01146 levels } & \multirow[t]{2}{*}{$x^{2}$} & \multirow[t]{2}{*}{$P$ value } \\
\hline & & $\begin{array}{l}\text { Low } \\
\text { expression }\end{array}$ & $\begin{array}{l}\text { High } \\
\text { expression }\end{array}$ & & \\
\hline \multicolumn{4}{|l|}{ Ages (years) } & 0.97 & 0.325 \\
\hline$\geq 50$ & 66 & 31 & 35 & & \\
\hline$<50$ & 22 & 13 & 9 & & \\
\hline \multicolumn{4}{|l|}{ Sex } & 0.09 & 0.764 \\
\hline Male & 75 & 37 & 38 & & \\
\hline Female & 13 & 8 & 5 & & \\
\hline \multicolumn{4}{|l|}{ Liver cirrhosis } & 0.77 & 0.381 \\
\hline Negative & 34 & 15 & 19 & & \\
\hline Positive & 54 & 29 & 25 & & \\
\hline \multicolumn{4}{|c|}{ Alpha fetoprotein } & 3.14 & 0.076 \\
\hline$\leq 400 \mathrm{ng} / \mathrm{ml}$ & 32 & 12 & 20 & & \\
\hline$>400 \mathrm{ng} / \mathrm{ml}$ & 56 & 32 & 24 & & \\
\hline \multicolumn{4}{|l|}{ Tumour size } & 8.02 & 0.005 \\
\hline$<5 \mathrm{~cm}$ & 35 & 11 & 24 & & \\
\hline$\geq 5 \mathrm{~cm}$ & 53 & 33 & 20 & & \\
\hline \multicolumn{4}{|c|}{ Tumour number } & 5.44 & 0.020 \\
\hline Single & 74 & 33 & 41 & & \\
\hline Multiple & 14 & 11 & 3 & & \\
\hline \multicolumn{4}{|c|}{ Microvascular invasion } & 4.55 & 0.033 \\
\hline Negative & 45 & 17 & 27 & & \\
\hline Positive & 43 & 27 & 17 & & \\
\hline \multicolumn{4}{|c|}{ Satellite nodules } & 7.31 & 0.007 \\
\hline Negative & 75 & 33 & 42 & & \\
\hline Positive & 13 & 11 & 2 & & \\
\hline \multicolumn{4}{|c|}{ Distant metastasis } & 0.30 & 0.584 \\
\hline Negative & 85 & 43 & 42 & & \\
\hline Positive & 3 & 2 & 1 & & \\
\hline \multicolumn{4}{|c|}{ Lymphatic metastasis } & 0.16 & 0.694 \\
\hline Negative & 81 & 41 & 40 & & \\
\hline Positive & 7 & 3 & 4 & & \\
\hline \multicolumn{4}{|c|}{ DNA content of HBV } & 5.57 & 0.018 \\
\hline Negative & 49 & 19 & 30 & & \\
\hline Positive & 39 & 25 & 14 & & \\
\hline \multicolumn{4}{|c|}{ Edmondson-Steiner grade } & 1.25 & 0.265 \\
\hline$I+\|$ & 31 & 13 & 18 & & \\
\hline$I I I+I V$ & 57 & 31 & 26 & & \\
\hline \multicolumn{4}{|c|}{ Barcelona clinic liver cancer grade (BCLC) } & 9.19 & 0.010 \\
\hline A & 44 & 15 & 29 & & \\
\hline B & 18 & 11 & 7 & & \\
\hline C & 26 & 18 & 8 & & \\
\hline
\end{tabular}

\section{Functional and pathway enrichment analysis}

The GEPIA, MEM, and TANRIC websites were utilized to screen for promising coexpressed genes related to
LINC01146. Specifically, 199, 1443, and 204 potential coexpressed genes were found on the GEPIA, MEM, and TANRIC websites, respectively, and 107 overlapping coexpressed genes were subsequently screened out for deeper functional and pathway enrichment analyses (Fig. 8A). The results of GO enrichment analysis indicated that these overlapping coexpressed genes were mainly involved in "small molecule metabolism", "carboxylic acid metabolism", "organic acid metabolism", "ketoacid metabolism", "small molecule decomposition" and other biological processes (Fig. 8B). The KEGG pathway enrichment analysis showed that these genes were mainly enriched in "metabolic pathway", "complement and coagulation cascade", "retinol metabolism", "caffeine metabolism", "propionic acid metabolism" and other pathways (Fig. 8C).

\section{Construction of the PPI network and identification of core genes}

The STRING online website was used to construct a PPI network of 107 overlapping coexpressed genes to reveal their mutual associations. The results showed that the network has a total of 100 nodes and 181 edges, with an average node degree of 3.62 and an average local clustering coefficient of $0.37(P<1.0 \mathrm{E}-16$, Fig. 8D). Subsequently, we used the MCODE plug-in of Cytoscape software to screen for core genes. The results showed that FETUB (Fetuin-B), TTR (transthyretin), LPA [lipoprotein(a)], $A L D H 8 A 1$ (aldehyde dehydrogenase 8 family member), SERPINA4 (serpin family A member 4), $A G X T$ (alanine-glyoxylate and serine-pyruvate), $A P O H$ (apolipoprotein H), SERPINF2 (Serpin family F member 2), F13B (Coagulation factor XIII B chain), ORM2 (Orosomucoid 2), KNG1 (kininogen 1), and F11 (Coagulation factor XI) were the 12 most significant core genes (Fig. 8E).

In addition, we explored the expression levels of these 12 core genes in HCC tissues based on the TCGA database and found that they were all lower in HCC tissues than in adjacent normal tissues (all $P<0.001$, Table 4). Pearson correlation analysis was used to explore the correlation between LINC01146 and these 12 core genes. The results indicated that LINC001146 had the strongest correlation with FETUB $(P<0.001)$ and TTR $(P<0.001)$ among these 12 core genes, and the details are shown in Table 4.

\section{Discussion}

In the present study, we identified LINC01146 as a novel liver-specific IncRNA. We showed that LINC01146 was decreased in HCC tissues and expression of LINC01146 
Table 3 Univariate and multivariate Cox's proportional risk model for overall survival of HCC patients $(n=85)$

\begin{tabular}{|c|c|c|c|c|c|c|c|c|}
\hline \multirow[t]{2}{*}{ Variables } & \multicolumn{4}{|c|}{ Univariate analysis } & \multicolumn{4}{|c|}{ Multivariable analysis } \\
\hline & $\beta$ & HR & $95 \% \mathrm{Cl}$ & $P$ value & $\beta$ & HR & $95 \% \mathrm{Cl}$ & $P$ value \\
\hline Age $(\geq 50$ vs. $<50)$ & 0.03 & 1.03 & $0.99-1.06$ & 0.135 & & & & \\
\hline Sex (male vs. female) & -0.11 & 0.89 & $0.31-2.63$ & 0.837 & & & & \\
\hline Liver cirrhosis (positive vs. negative) & 0.13 & 1.14 & $0.49-2.67$ & 0.757 & & & & \\
\hline $\operatorname{AFP}(>400 \mathrm{ng} / \mathrm{ml} \mathrm{vs} . \leq 400 \mathrm{ng} / \mathrm{ml}$ ) & 0.93 & 2.54 & $0.87-7.45$ & 0.090 & & & & \\
\hline Tumour size ( $\geq 5 \mathrm{~cm}$ vs. $<5 \mathrm{~cm})$ & 0.81 & 2.25 & $0.89-5.69$ & 0.087 & & & & \\
\hline Tumour number (multiple vs. single) & 0.12 & 1.13 & $0.39-3.31$ & 0.822 & & & & \\
\hline Distant metastasis (positive vs. negative) & 1.23 & 3.42 & $0.44-26.73$ & 0.242 & & & & \\
\hline Lymphatic metastasis (positive vs. negative) & 0.61 & 1.85 & $0.55-6.21$ & 0.323 & & & & \\
\hline DNA content of HBV (positive vs. negative) & 0.12 & 1.13 & $0.50-2.53$ & 0.768 & & & & \\
\hline Satellite nodules (positive vs. negative) & 1.35 & 3.86 & $1.59-9.40$ & 0.003 & 0.92 & 2.51 & $0.78-8.08$ & 0.124 \\
\hline BCLC grade (A vs. B vs. C) & 0.42 & 1.53 & $0.98-2.38$ & 0.061 & 0.01 & 1.01 & $0.57-1.79$ & 0.983 \\
\hline MVI (positive vs. negative) & 0.89 & 2.43 & $1.46-4.04$ & 0.001 & 2.04 & 7.73 & $2.24-26.72$ & 0.001 \\
\hline Edmondson-Steiner grade (> I| vs. I-II) & 1.91 & 6.73 & $1.58-28.63$ & 0.010 & 2.36 & 10.57 & $2.14-52.15$ & 0.004 \\
\hline LINC01146 expression (high vs. low) & -1.32 & 0.27 & $0.09-0.78$ & 0.015 & -0.97 & 0.38 & $0.16-0.92$ & 0.033 \\
\hline
\end{tabular}

vs. versus, AFP alpha fetoprotein, $B C L C$ : Barcelona clinic liver cancer grade, $M V I$ microvascular invasion

was negatively related to the aggressive clinical features and poor prognosis of HCC patients. Furthermore, overexpression of LINC01146 inhibited the proliferation, migration, and invasion while promoting the apoptosis of HCC cells in vitro. In contrast, downregulation of LINC01146 exerted the opposite effects. Moreover, overexpression of LINC01146 inhibited the tumour growth of HCC cells in vivo, while downregulation of LINC01146 played the opposite role in vivo. All of the above results indicated that LINC01146 may play a cancer-inhibiting role in $\mathrm{HCC}$ progression.

HCC patients with aggressive clinical features are prone to recurrence, metastasis, and poor prognosis. Previous studies have shown that MVI indicates the metastasis of HCC, and patients with positive MVI have a poor prognosis $[35,36]$. The increase in tumour size is one of the signals of metastasis in HCC patients and is directly proportional to the risk of metastasis in HCC patients [37]. Additionally, the presence of satellite nodules in the pathological diagnosis of HCC patients shows invasion of cancer cells and suggests poor prognosis of HCC patients and increased proneness to symptom recurrence $[38,39]$. A great deal of evidence suggests that lncRNAs can serve as molecular targets to predict the prognosis of HCC patients, such as lncRNA DGCR5, lncRNA GAS5-AS1, lncRNA miR210Hg, and lncRNA SNHG16 [40-43]. In our study, we found for the first time that low expression of LINC01146 was associated with aggressive clinical features, including tumour size, tumour number, MVI, satellite nodules, DNA content of HBV, and $B C L C$ grade. In addition, we found that low expression of LINC01146 was associated with poor prognosis in HCC patients. These results suggested that low expression of LINC01146 may affect the progression and prognosis of HCC patients and may serve as a tumour inhibitor and a prognostic molecular marker for HCC patients.

In the present study, we identified LINC01146 as a liver-specific lncRNA enriched in normal liver tissues based on the GTEx database and involved in the proliferation, migration, invasion, and apoptosis of HCC cells. Recently, more studies have shown that tissuespecific lncRNAs play an important role in the development of cancers. For instance, two tissue-specific lncRNAs, PCAT18 and LINC01133, were enriched in normal stomach tissues and downregulated in gastric cancer (GC) [44]. PCAT18 acts as a cancer inhibitor by impairing the viability, invasion, and migration of GC cells [45]. LINC01133 inhibits the proliferation, migration, and epithelial-mesenchymal transition (EMT) of GC cells by silencing the Wnt/ $\beta$-catenin pathway [46]. LncRNA TINCR plays a tissue-specific role in normal skin, placenta, and oesophageal tissues [47]. Several studies have reported that TINCR plays a cancer suppressive role in lung cancer, breast cancer, and prostate cancer by inhibiting biological characteristics, such as proliferation, migration, and invasion of cancer cells 

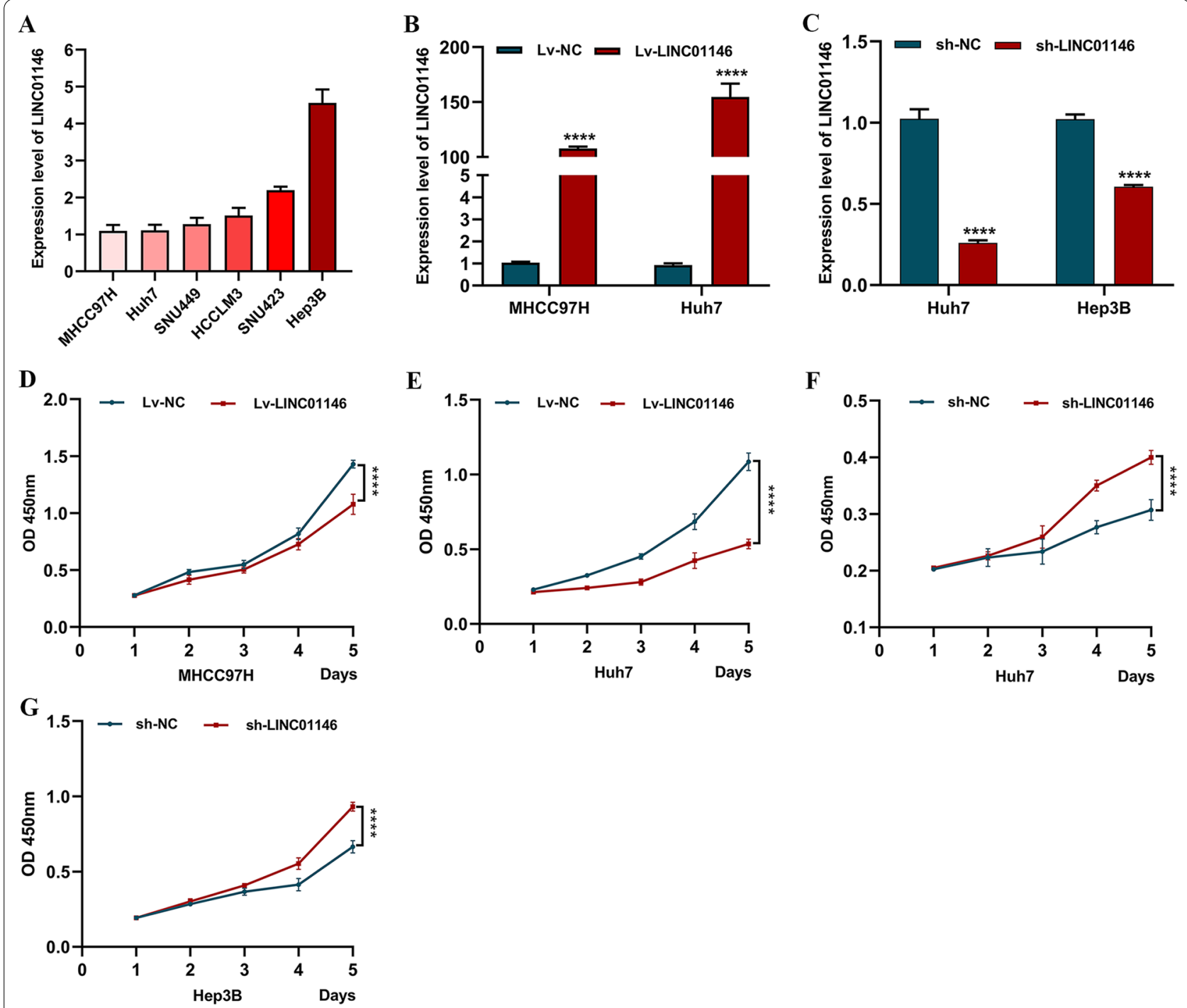

Fig. 2 The effect of LINC01146 on the proliferation of HCC cells in vitro. A The expression of LINC01146 in six HCC cell lines. B Overexpression of LINC01146 was successfully achieved in MHCC97H and Huh7 cells. C Downregulation of LINC01146 was successfully achieved in Huh7 and Hep3B cells. D, E Overexpression of LINC01146 inhibited the proliferation of MHCC97H and Huh7 cells. F, G Downregulation of LINC01146 promoted the proliferation of Huh7 and Hep3B cells. ${ }^{* * *} P<0.001$

[48-50]. These findings suggest that tissue-specific lncRNAs may play an inhibitory role in tumourigenesis.

The negative correlation between the expression of LINC01146, MVI, and satellite nodules prompted us to hypothesize that LINC01146 may be involved in the proliferation, migration, invasion, and apoptosis of HCC cells. Rapid proliferation is one of the most important biological characteristics of HCC cells [51]. LncRNAs can affect the proliferation of HCC cells by targeting key regulatory factors in different pathways.
For instance, lncRNA MALAT1 promotes HCC cell proliferation by regulating expression of the oncogenic transcription factor B-MYB to facilitate cell cycle progression [52]. Overexpressed lncRNA SNHG16 sponges hsa-miR-93 and inhibits the proliferation of HCC cells [53]. The upregulation of IncRNA FAM83HAS1 promotes HCC cell proliferation through the Wnt/ $\beta$-catenin pathway [54]. Previous studies also revealed that HCC patients harbouring cancer cells with high migration and invasion activities often have increased 
A

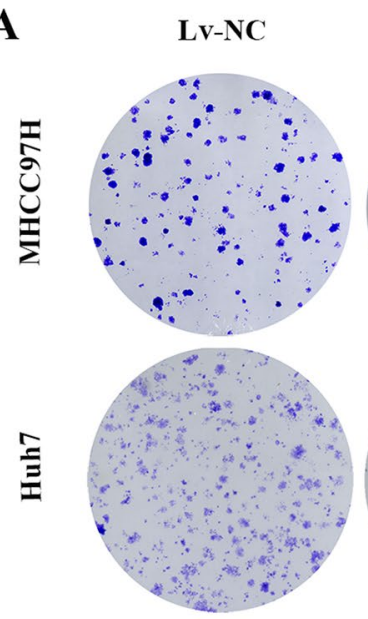

B

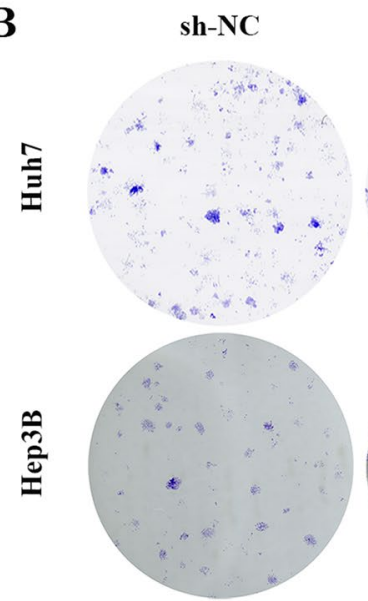

Lv-LINC01146

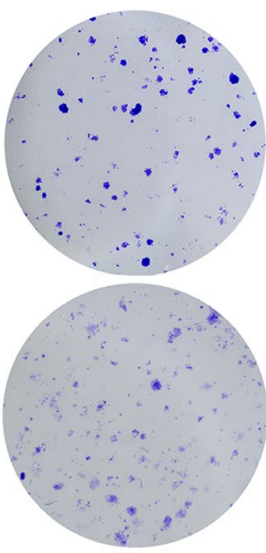

sh-LINC01146

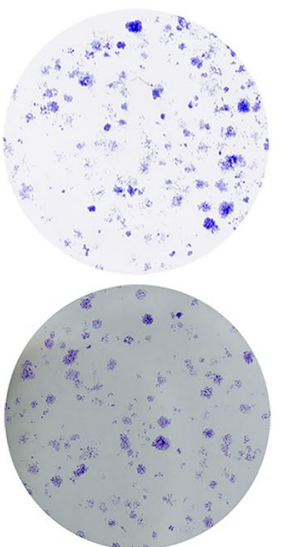

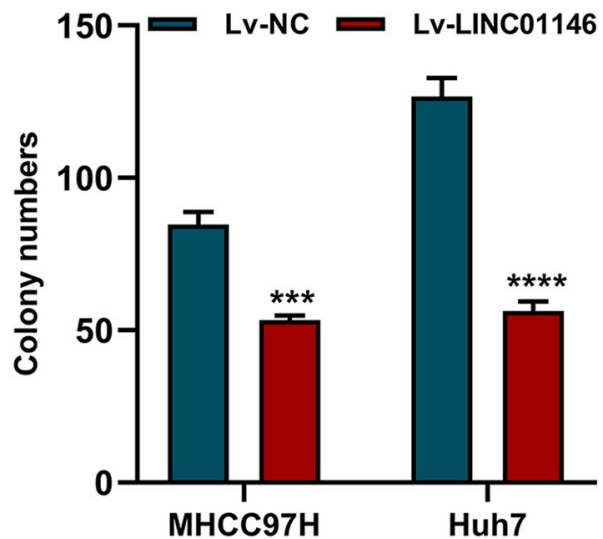

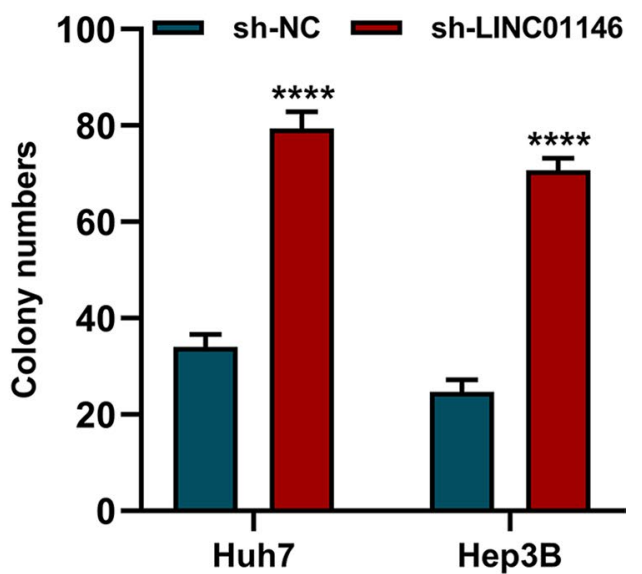

Fig. 3 LINC01146 affects the clone formation ability of HCC cells in vitro. A Overexpression of LINC01146 inhibited the clone formation abilities of MHCC97H and Huh7 cells. B Downregulation of LINC01146 promoted the clone formation abilities of Huh7 and Hep3B cells. ${ }^{* *} P<0.01$; ****P $<0.001$

aggressiveness, recurrence, and poor survival. For example, lncRNA MYLK-AS1 facilitates HCC progression and angiogenesis by promoting the invasion and metastatic abilities of HCC cells in vivo through targeting the miR-424-5p/E2F7 axis and activating the VEGFR-2 signalling pathway [55]. LncRNA HAND2AS1 inhibits the proliferation, migration, and invasion of SNU-398 cells by mediating the downregulation of ROCK2 protein in HCC [56]. Silencing of LINC00240 suppresses the migration and invasion of HCC cells by promoting miR-4465 and inhibiting the HGF/c-Met signalling pathway [57]. In the present study, by overexpressing and knocking down LINC01146, we found that LINC01146 inhibited the proliferation, migration, and invasion abilities of HCC cells in vitro and promoted their apoptosis. Additionally, LINC01146 inhibited the growth of tumours in vivo. These results suggest that LINC01146 may play a cancer-inhibiting role in HCC by reducing biological characteristics of $\mathrm{HCC}$ cells, such as proliferation, migration, and invasion, and promoting apoptosis.

Previous studies have reported that lncRNAs influence the occurrence and progression of tumours by participating in a variety of pathways. We found that the coexpressed genes of LINC01146 were mainly involved in "metabolic pathway", "complement and coagulation cascade", "retinol metabolism", "caffeine metabolism" and other pathways. The reprogramming 


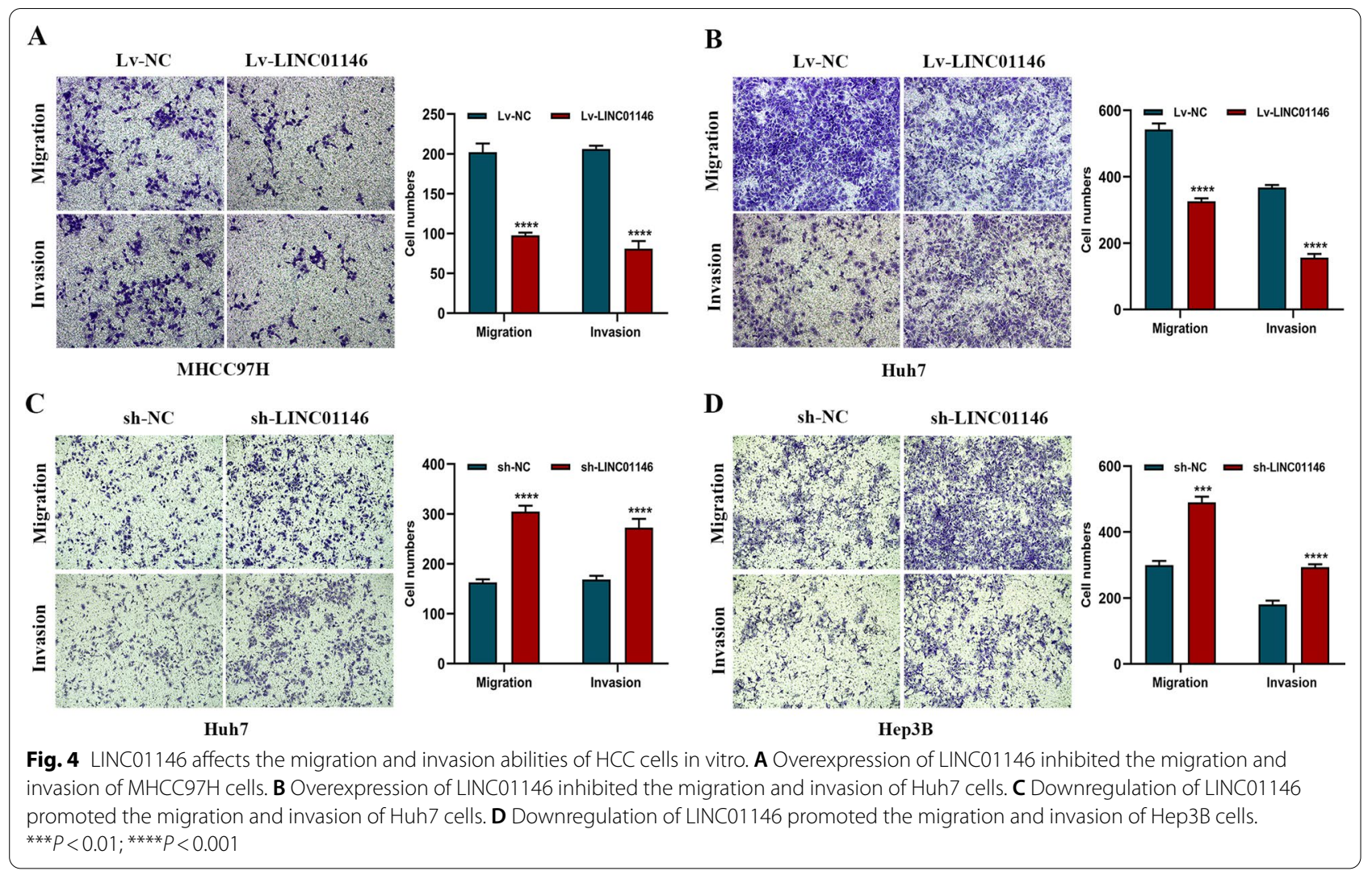

of cell energy metabolism, which provides an energetic basis for the unrestricted proliferation and metastasis of cancer cells, is widely recognized as an emerging cancer marker. Metabolic reprogramming plays a key role in promoting tumour survival and proliferation to sustain the increasing metabolic demands of cancer cells $[58,59]$. In recent years, complement and coagulation cascades have played crucial roles in the carcinogenesis and progression of cancer [60-62]. Complement cascades contribute to the development of the major features of carcinogenesis, including the maintenance of cell proliferation, inhibition of apoptosis, and promotion of cell invasion [63]. In addition, many bioinformatic studies have shown that retinol metabolism plays an important role in the occurrence and development of HCC [64-66]. Caffeine has also been reported to have an antitumour effect and can protect liver function. Edling et al. found that caffeine blocks the proliferation of HCC and pancreatic cancer adenocarcinoma cells by inhibiting the PI3K/ Akt pathway [67]. Moreover, Okano et al. reported that caffeine inhibits the proliferation of HCC cells by activating the MEK/ERK/EGFR signalling pathway [68]. We also found a strong correlation between the expression levels of FETUB/TTR and LINC01146 in HCC. However, we only discovered this relationship through the TCGA database and did not verify it through experimental methods, which requires further study.

In conclusion, LINC01146 is downregulated in HCC tissues and negatively correlated with aggressive clinical features and poor prognosis of HCC patients. It may serve as a prognostic biomarker for HCC patients and a cancer suppressor by repressing the proliferation, migration, and invasion abilities of HCC cells, while promoting the apoptosis of HCC cells. 


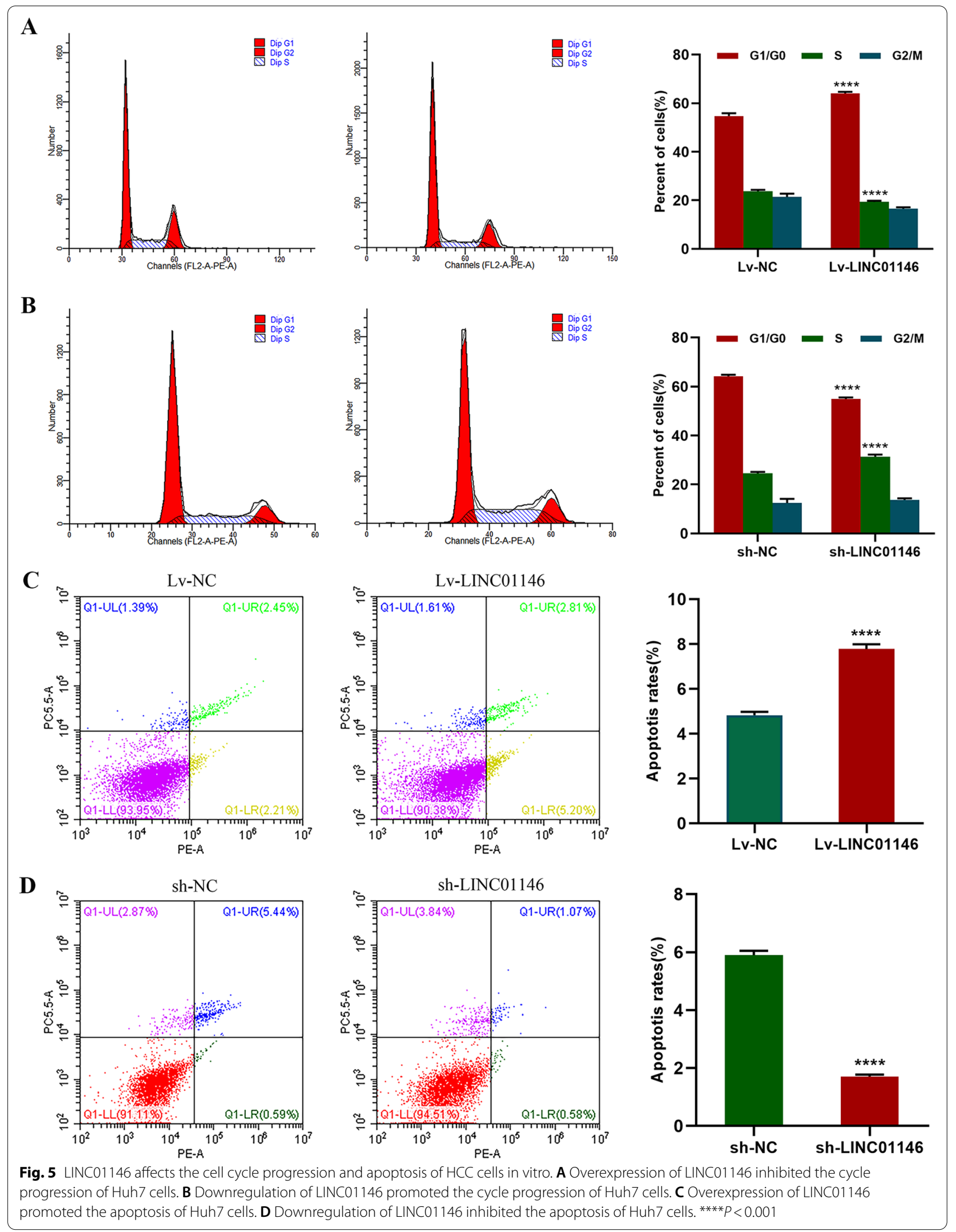


A

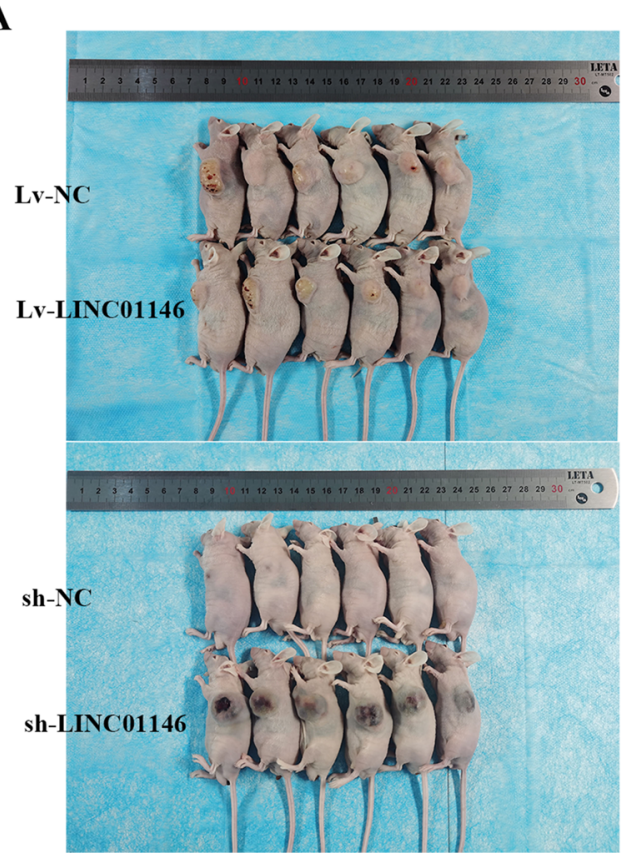

C

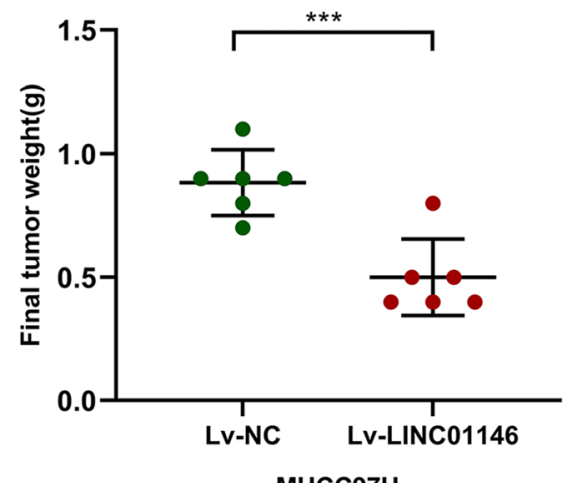

$\mathbf{E}$

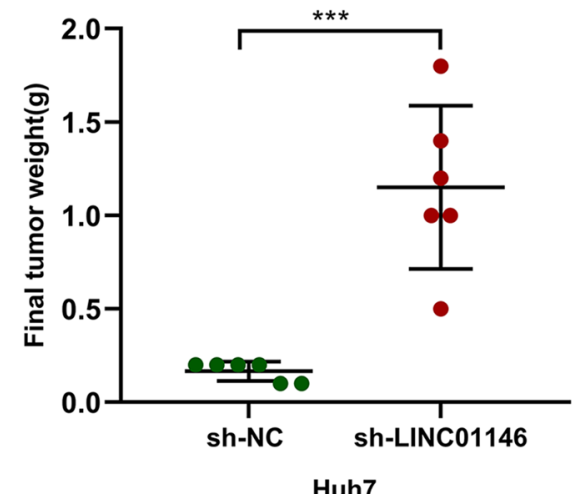

B

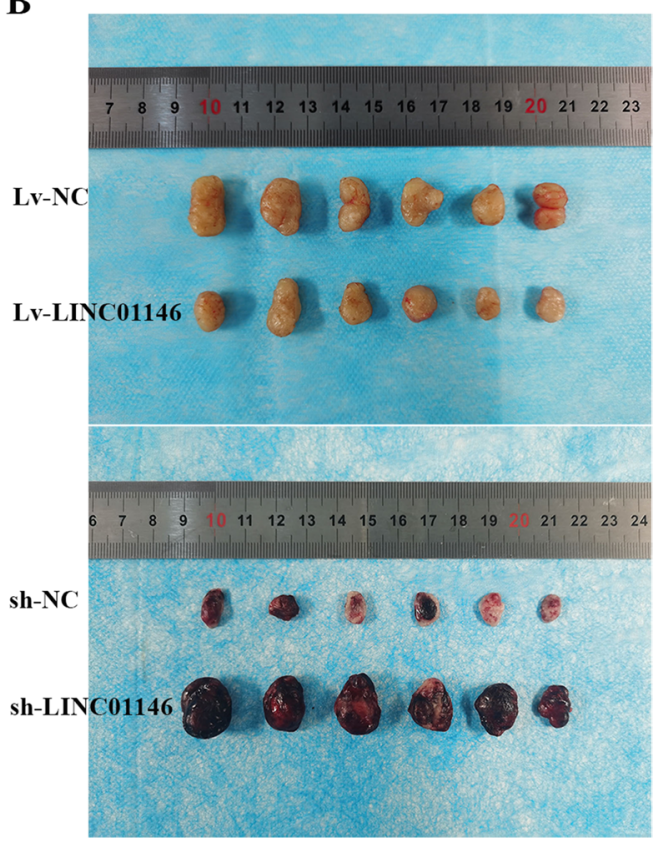

D

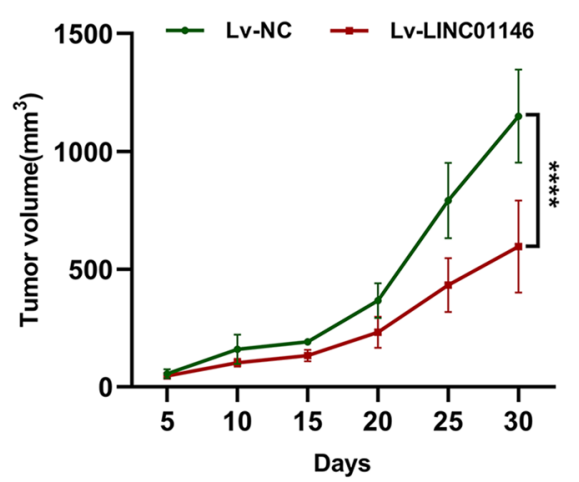

F

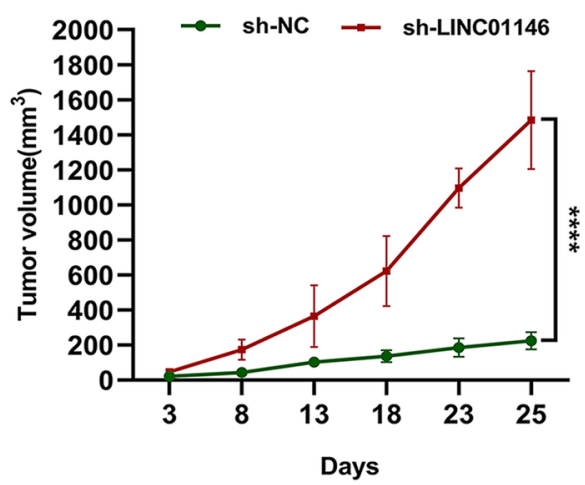

Fig. 6 LINC01146 affects the tumour growth of HCC cells in vivo. A, B Construction of the tumor formation model in nude mice. C, D Overexpression of LINC01146 inhibited the tumour growth of HCC cells in nude mice. E, F Downregulation of LINC01146 promoted the tumour growth of HCC cells in nude mice. ${ }^{* *} P<0.01 ;{ }^{* * *} P<0.001$ 
A

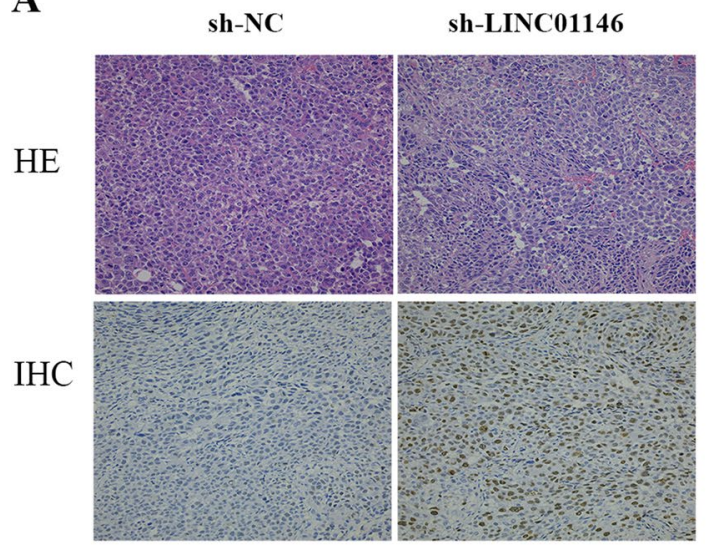

B

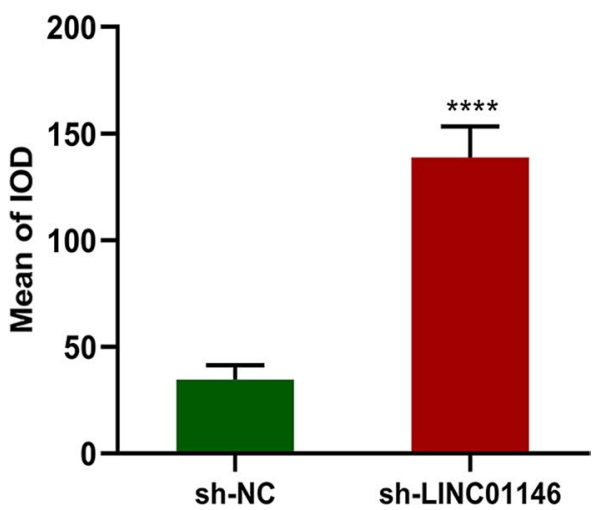

Fig. 7 Downregulation of LINC01146 promotes the tumour growth of HCC cells in vivo. A The results of HE and IHC staining of tumour tissues of nude mice. B Downregulation of LINC01146 promoted the positive expression of Ki-67 protein. ${ }^{* * *} P<0.001$

A

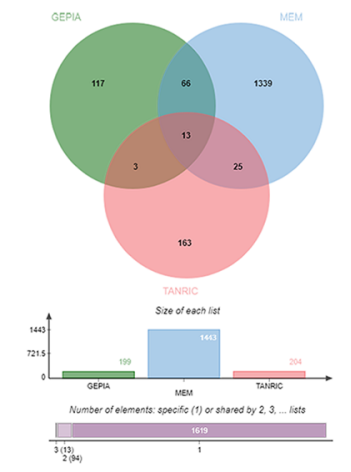

B

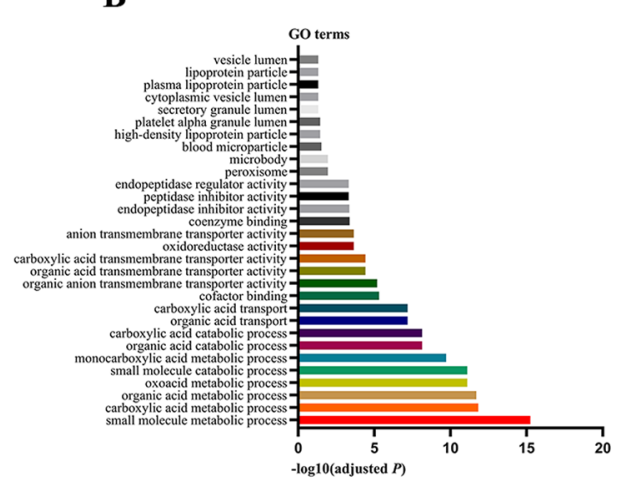

C

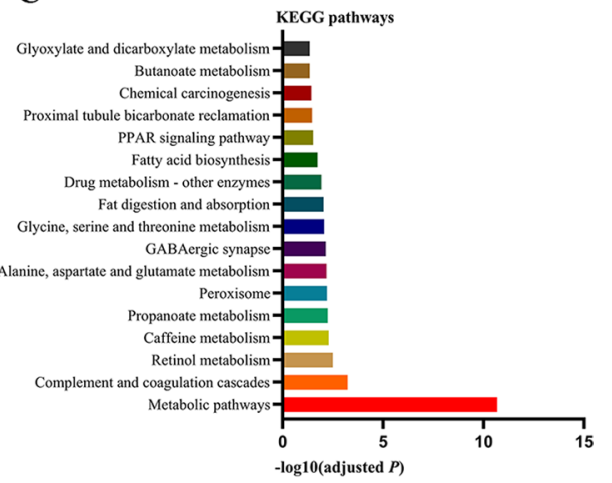

D

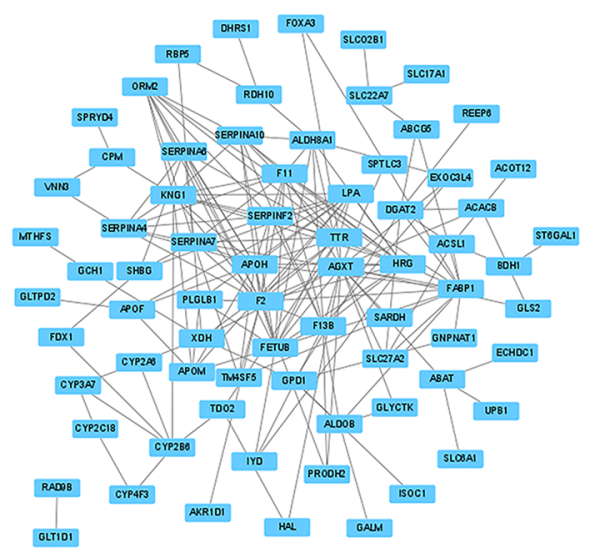

$\mathbf{E}$

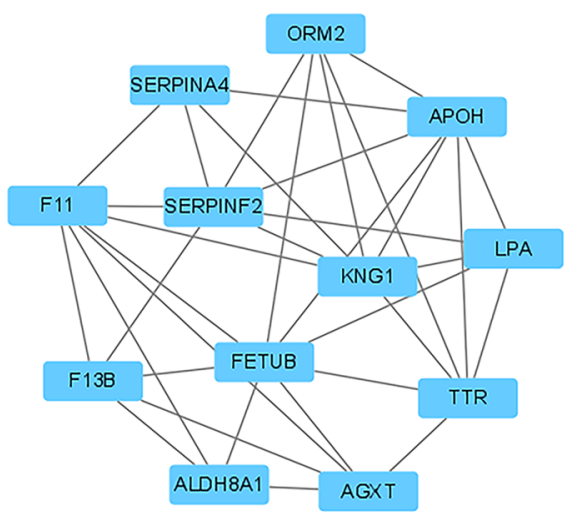

Fig. 8 Pathway enrichment analyses and PPI network of LINC01146 in HCC. A A Venn diagram was used to identify intersecting genes using the GEPIA, MEM, and TANRIC websites. B Significant GO terms were enriched using the WebGestalt website. C Significant KEGG pathways were identified by the KOBAS 3.0 website. D, E The PPI network and core genes of the coexpressed genes were constructed by Cytoscape software 
Table 4 The expression levels of core genes in HCC tissues and the correlation between core genes and LINC01146

\begin{tabular}{|c|c|c|c|c|c|c|c|}
\hline \multirow[t]{2}{*}{ Core genes } & \multirow[t]{2}{*}{ Tissue types } & \multirow[t]{2}{*}{$\mathbf{N}$} & \multirow[t]{2}{*}{ Expression $(X \pm \mathbf{s})$} & \multirow[t]{2}{*}{$t$} & \multirow[t]{2}{*}{$P$ value } & \multicolumn{2}{|c|}{ Pearson correlation } \\
\hline & & & & & & $r$ & $P$ value \\
\hline \multirow[t]{2}{*}{ FETUB } & HCC tissue & 371 & $5.45 \pm 2.40$ & -12.00 & $<0.001$ & 0.56 & $<0.001$ \\
\hline & Normal tissue & 50 & $7.28 \pm 0.62$ & & & & \\
\hline \multirow[t]{2}{*}{ TTR } & HCC tissue & 371 & $10.14 \pm 2.78$ & -11.83 & $<0.001$ & 0.53 & $<0.001$ \\
\hline & Normal tissue & 50 & $11.93 \pm 0.76$ & & & & \\
\hline \multirow[t]{2}{*}{ LPA } & HCC tissue & 371 & $2.69 \pm 1.37$ & -17.29 & $<0.001$ & 0.49 & $<0.001$ \\
\hline & Normal tissue & 50 & $4.83 \pm 0.72$ & & & & \\
\hline \multirow[t]{2}{*}{ ALDH8A1 } & HCC tissue & 371 & $5.49 \pm 1.66$ & -18.96 & $<0.001$ & 0.46 & $<0.001$ \\
\hline & Normal tissue & 50 & $7.33 \pm 0.32$ & & & & \\
\hline \multirow[t]{2}{*}{ SERPINA4 } & HCC tissue & 371 & $7.26 \pm 1.89$ & -8.81 & $<0.001$ & 0.46 & $<0.001$ \\
\hline & Normal tissue & 50 & $8.37 \pm 0.57$ & & & & \\
\hline \multirow[t]{2}{*}{ AGXT } & HCC tissue & 371 & $8.56 \pm 2.08$ & -11.13 & $<0.001$ & 0.45 & $<0.001$ \\
\hline & Normal tissue & 50 & $9.88 \pm 0.34$ & & & & \\
\hline \multirow[t]{2}{*}{$\mathrm{APOH}$} & HCC tissue & 371 & $12.29 \pm 1.98$ & -8.09 & $<0.001$ & 0.44 & $<0.001$ \\
\hline & Normal tissue & 50 & $13.20 \pm 0.32$ & & & & \\
\hline \multirow[t]{2}{*}{ SERPINF2 } & HCC tissue & 371 & $9.72 \pm 1.62$ & -11.53 & $<0.001$ & 0.43 & $<0.001$ \\
\hline & Normal tissue & 50 & $10.78 \pm 0.27$ & & & & \\
\hline \multirow[t]{2}{*}{ F13B } & HCC tissue & 371 & $6.26 \pm 1.75$ & -3.53 & $<0.001$ & 0.41 & $<0.001$ \\
\hline & Normal tissue & 50 & $6.65 \pm 0.45$ & & & & \\
\hline \multirow[t]{2}{*}{ ORM2 } & HCC tissue & 371 & $10.51 \pm 1.69$ & -11.97 & $<0.001$ & 0.38 & $<0.001$ \\
\hline & Normal tissue & 50 & $11.96 \pm 1.69$ & & & & \\
\hline \multirow[t]{2}{*}{ KNG1 } & HCC tissue & 371 & $10.00 \pm 1.89$ & -4.08 & $<0.001$ & 0.37 & $<0.001$ \\
\hline & Normal tissue & 50 & $10.44 \pm 0.32$ & & & & \\
\hline \multirow[t]{2}{*}{ F11 } & HCC tissue & 371 & $5.01 \pm 1.34$ & -10.20 & $<0.001$ & 0.32 & $<0.001$ \\
\hline & Normal tissue & 50 & $5.97 \pm 0.45$ & & & & \\
\hline
\end{tabular}

\section{Supplementary Information}

The online version contains supplementary material available at https://doi. org/10.1186/s12967-021-03225-2.

Additional file 1: Figure S1. The supplementary materials for LINC01146. A Volcano map of differentially expressed IncRNAs in the GSE93789 microarray dataset. B LINC01146 was specifically expressed in normal liver tissues. C No apparent publication bias was observed in this meta-analysis by funnel plot. D The results of this meta-analysis were stable by sensitivity analysis.

Additional file 2: Table S1. The expression of LINC01146 in GSE93789 microarray.

\section{Acknowledgements}

We acknowledge the Guangxi Colleges and Universities Key Laboratory of Prevention, the Guangxi Medical University Laboratory Animal Center, and Control of Highly Prevalent Diseases and Academician Dongxin Lin workstation.

\section{Authors' contributions}

XM, MM, and SL contributed to conception and design of the study. MM and JT organized the database and CT performed the statistical analysis. $\mathrm{HH}$ and BL completed the data collection. XM wrote the first draft of the manuscript. $\mathrm{DH}, \mathrm{XZ}$, and $\mathrm{XQ}$ made critical revisions and approved the final manuscript. Al authors contributed to manuscript revision. All authors read and approved the final manuscript.

\section{Funding}

This work was supported by the National Natural Science Foundation of China (81960613 and 81660563), Natural Science Foundation of Guangxi Province (2018GXNSFBA138003), and Key Laboratory of Early Prevention and Treatment for Regional High Frequency Tumor (Guangxi Medical University), Ministry of Education (GKE-ZZ202001).

\section{Availability of data and materials}

The datasets used and/or analyzed during the current study are available from the corresponding author on reasonable request.

\section{Declarations}

Ethics approval and consent to participate

The animal study was reviewed and approved by the Guangxi Medical University Laboratory Animal Center [SYXKGUI 2020-0004]. The studies involving human participants were reviewed and approved by the Ethics Committee of Guangxi Medical University. The patients/participants provided their written informed consent to participate in this study.

\section{Consent for publication}

All authors have approved the manuscript for submission.

\section{Competing interests}

The authors declare that they have no competing interests. 


\begin{abstract}
Author details
${ }^{1}$ Department of Epidemiology, School of Public Health, Guangxi Medical University, Nanning, Guangxi, China. ${ }^{2}$ Department of Epidemiology, School of Public Health, Cheeloo College of Medicine, Shandong University, Jinan, Shandong, China. ${ }^{3}$ Yong Loo Lin School of Medicine, National University of Singapore, 10 Medical Dr, Singapore, Singapore. ${ }^{4}$ Department of Sanitary Chemistry, School of Public Health, Guangxi Medical University, Nanning, Guangxi, China. ${ }^{5}$ Department of Maternal, Child and Adolescent Health, School of Public Health, Guangxi Medical University, Nanning, Guangxi, China. ${ }^{6}$ Key Laboratory of Early Prevention and Treatment for Regional High Frequency Tumor (Guangxi Medical University), Ministry of Education, Nanning, Guangxi, China.
\end{abstract}

\section{Received: 19 November 2021 Accepted: 29 December 2021}

Published online: 31 January 2022

\section{References}

1. Sung H, Ferlay J, Siegel RL, Laversanne M, Soerjomataram I, Jemal A, et al. Global cancer statistics 2020: GLOBOCAN estimates of incidence and mortality worldwide for 36 cancers in 185 countries. CA Cancer J Clin. 2021;71(3):209-49.

2. Feng RM, Zong YN, Cao SM, Xu RH. Current cancer situation in China: good or bad news from the 2018 global cancer statistics? Cancer Commun. 2019;39(1):22.

3. Kim SR, Kudo M, Hino O, Han KH, Chung YH, Lee HS. Epidemiology of hepatocellular carcinoma in Japan and Korea. A review. Oncology. 2008;75(Suppl 1):13-6.

4. Esnaola NF, Mirza N, Lauwers GY, Ikai I, Regimbeau JM, Belghiti J, et al. Comparison of clinicopathologic characteristics and outcomes after resection in patients with hepatocellular carcinoma treated in the United States, France, and Japan. Ann Surg. 2003;238(5):711-9.

5. Kim J, Kang W, Sinn DH, Gwak GY, Paik YH, Choi MS, et al. Substantial risk of recurrence even after 5 recurrence-free years in early-stage hepatocellular carcinoma patients. Clin Mol Hepatol. 2020;26(4):516-28.

6. Lv D, Wang Y, Zhang Y, Cui P, Xu Y. Downregulated long non-coding RNA DREH promotes cell proliferation in hepatitis B virus-associated hepatocellular carcinoma. Oncol Lett. 2017;14(2):2025-32.

7. Zhou M, Zhang XY, Yu X. Overexpression of the long non-coding RNA SPRY4-IT1 promotes tumor cell proliferation and invasion by activating EZH2 in hepatocellular carcinoma. Biomed Pharmacother = Biomedecine \& pharmacotherapie. 2017:85:348-54

8. Liu N, Liu Q, Yang X, Zhang F, Li X, Ma Y, et al. Hepatitis B virus-upregulated LNC-HUR1 promotes cell proliferation and tumorigenesis by blocking p53 activity. Hepatology. 2018;68(6):2130-44

9. Tsang FH, Au SL, Wei L, Fan DN, Lee JM, Wong CC, et al. Long noncoding RNA HOTTIP is frequently up-regulated in hepatocellular carcinoma and is targeted by tumour suppressive miR-125b. Liver Int. 2015;35(5):1597-606.

10. Quagliata L, Matter MS, Piscuoglio S, Arabi L, Ruiz C, Procino A, et al. Long noncoding RNA HOTTIP/HOXA13 expression is associated with disease progression and predicts outcome in hepatocellular carcinoma patients. Hepatology. 2014;59(3):911-23.

11. Yao J, Fu J, Liu Y, Qu W, Wang G, Yan Z. LncRNA CASC9 promotes proliferation, migration and inhibits apoptosis of hepatocellular carcinoma cells by down-regulating miR-424-5p. Ann Hepatol. 2020;23: 100297.

12. Li J, Zhai DS, Huang Q, Chen HL, Zhang Z, Tan QF. LncRNA DCST1-AS1 accelerates the proliferation, metastasis and autophagy of hepatocellular carcinoma cell by AKT/mTOR signaling pathways. Eur Rev Med Pharmacol Sci. 2019;23(14):6091-104.

13. Huang JL, Cao SW, Ou QS, Yang B, Zheng SH, Tang J, et al. The long noncoding RNA PTTG3P promotes cell growth and metastasis via up-regulating PTTG1 and activating PI3K/AKT signaling in hepatocellular carcinoma. Mol Cancer. 2018;17(1):93.

14. Xu J, Lu Y, Liu Q, Xia A, Zhao J, Xu X, et al. Long noncoding RNA GMAN promotes hepatocellular carcinoma progression by interacting with elF4B. Cancer Lett. 2020;473:1-12.

15. Zhang L, Wang Y, Sun J, Ma H, Guo C. LINC00205 promotes proliferation, migration and invasion of HCC cells by targeting miR-122-5p. Pathol Res Pract. 2019;215(9): 152515.
16. Song XZ, Ren XN, Xu XJ, Ruan XX, Wang YL, Yao TT. LncRNA RHPN1-AS1 promotes cell proliferation, migration and invasion through targeting miR-7-5 $p$ and activating PI3K/AKT/mTOR pathway in hepatocellular carcinoma. Technol Cancer Res Treat. 2020;19:1533033820957023.

17. Guo X, Wang Y. LncRNA TMPO-AS1 promotes hepatocellular carcinoma cell proliferation, migration and invasion through sponging miR-329-3p to stimulate FOXK1-mediated AKT/mTOR signaling pathway. Cancer Med. 2020;9(14):5235-46

18. Tsai WC, Hsu PW, Lai TC, Chau GY, Lin CW, Chen CM, et al. MicroRNA-122, a tumor suppressor microRNA that regulates intrahepatic metastasis of hepatocellular carcinoma. Hepatology. 2009;49(5):1571-82.

19. He J, Zuo Q, Hu B, Jin H, Wang C, Cheng Z, et al. A novel, liver-specific long noncoding RNA LINC01093 suppresses HCC progression by interaction with IGF2BP1 to facilitate decay of GLI1 mRNA. Cancer Lett. 2019;450:98-109.

20. Mo M, Liu S, Ma X, Tan C, Wei L, Sheng Y, et al. A liver-specific IncRNA, FAM99B, suppresses hepatocellular carcinoma progression through inhibition of cell proliferation, migration, and invasion. J Cancer Res Clin Oncol. 2019;145(8):2027-38

21. Ma X, Mo M, Tan HJJ, Tan C, Zeng X, Zhang G, et al. LINC02499, a novel liver-specific long non-coding RNA with potential diagnostic and prognostic value, inhibits hepatocellular carcinoma cell proliferation, migration, and invasion. Hepatol Res. 2020;50(6):726-40.

22. Fagerberg L, Hallström BM, Oksvold P, Kampf C, Djureinovic D, Odeberg J, et al. Analysis of the human tissue-specific expression by genome-wide integration of transcriptomics and antibody-based proteomics. Mol Cell Proteom. 2014;13(2):397-406.

23. Guo X. Differential gene analysis and preliminary verification of long noncoding RNA in hepatocellular carcinoma. Guangxi Medical University (Ph.D. dissertation). 2018.

24. Tomczak K, Czerwińska P, Wiznerowicz M. The Cancer Genome Atlas (TCGA): an immeasurable source of knowledge. Contemp Oncol. 2015;19(1a):A68-77.

25. Vera Alvarez R, Pongor LS, Mariño-Ramírez L, Landsman D. TPMCalculator: one-step software to quantify mRNA abundance of genomic features. Bioinformatics. 2019;35(11):1960-2.

26. Barrett T, Wilhite SE, Ledoux P, Evangelista C, Kim IF, Tomashevsky M, et al. NCBI GEO: archive for functional genomics data sets-update. Nucleic Acids Res. 2013;41(Database issue):D991-5.

27. Guo Y, Wang L, Ma R, Mu Q, Yu N, Zhang Y, et al. JiangTang XiaoKe granule attenuates cathepsin $\mathrm{K}$ expression and improves IGF-1 expression in the bone of high fat diet induced KK-Ay diabetic mice. Life Sci. 2016;148:24-30.

28. Liu H, Zhu R, Liu C, Ma R, Wang L, Chen B, et al. Evaluation of decalcification techniques for rat femurs using $\mathrm{HE}$ and immunohistochemical staining. Biomed Res Int. 2017;2017:9050754.

29. Tang Z, Li C, Kang B, Gao G, Li C, Zhang Z. GEPIA: a web server for cancer and normal gene expression profiling and interactive analyses. Nucleic Acids Res. 2017;45(W1):W98-w102.

30. Ge H, Yan Y, Wu D, Huang Y, Tian F. Potential role of LINC00996 in colorectal cancer: a study based on data mining and bioinformatics. Onco Targets Ther. 2018;11:4845-55.

31. Li J, Han L, Roebuck P, Diao L, Liu L, Yuan Y, et al. TANRIC: an interactive open platform to explore the function of IncRNAs in cancer. Cancer Res. 2015;75(18):3728-37.

32. Liao Y, Wang J, Jaehnig EJ, Shi Z, Zhang B. WebGestalt 2019: gene set analysis toolkit with revamped UIs and APIs. Nucleic Acids Res. 2019;47(W1):W199-w205.

33. Shen S, Kong J, Qiu Y, Yang X, Wang W, Yan L. Identification of core genes and outcomes in hepatocellular carcinoma by bioinformatics analysis. J Cell Biochem. 2019;120(6):10069-81.

34. von Mering C, Jensen LJ, Snel B, Hooper SD, Krupp M, Foglierini M, et al. STRING: known and predicted protein-protein associations, integrated and transferred across organisms. Nucleic Acids Res. 2005;33(Database issue):D433-47.

35. Chen ZH, Zhang XP, Wang H, Chai ZT, Sun JX, Guo WX, et al. Effect of microvascular invasion on the postoperative long-term prognosis of solitary small HCC: a systematic review and meta-analysis. HPB. 2019;21(8):935-44. 
36. Du M, Chen L, Zhao J, Tian F, Zeng H, Tan Y, et al. Microvascular invasion (MVI) is a poorer prognostic predictor for small hepatocellular carcinoma. BMC Cancer. 2014;14:38.

37. Carr BI, Guerra V. Hepatocellular carcinoma extrahepatic metastasis in relation to tumor size and alkaline phosphatase levels. Oncology. 2016;90(3):136-42.

38. Xue R, Li R, Guo H, Guo L, Su Z, Ni X, et al. Variable intra-tumor genomic heterogeneity of multiple lesions in patients with hepatocellular carcinoma. Gastroenterology. 2016;150(4):998-1008.

39. Plessier A, Codes L, Consigny Y, Sommacale D, Dondero F, Cortes A, et al. Underestimation of the influence of satellite nodules as a risk factor for post-transplantation recurrence in patients with small hepatocellular carcinoma. Liver Transpl. 2004;10(2 Suppl 1):S86-90.

40. Huang $R$, Wang $X$, Zhang W, Zhangyuan G, Jin K, Yu W, et al. Down-regulation of LncRNA DGCR5 correlates with poor prognosis in hepatocellular carcinoma. Cell Physiol Biochem. 2016;40(3-4):707-15.

41. Wang Y, Jing W, Ma W, Liang C, Chai H, Tu J. Down-regulation of long noncoding RNA GAS5-AS1 and its prognostic and diagnostic significance in hepatocellular carcinoma. Cancer Biomark. 2018;22(2):227-36.

42. Wang Y, Li W, Chen X, Li Y, Wen P, XU F. MIR210HG predicts poor prognosis and functions as an oncogenic IncRNA in hepatocellular carcinoma. Biomed Pharmacothe $=$ Biomedecine \& pharmacotherapie. 2019;11:1297-301.

43. Zhong $J H$, Xiang $X$, Wang $Y Y$, Liu X, Qi LN, Luo CP, et al. The IncRNA SNHG16 affects prognosis in hepatocellular carcinoma by regulating p62 expression. J Cell Physiol. 2020;235(2):1090-102.

44. Foroughi K, Amini M, Atashi A, Mahmoodzadeh H, Hamann U, Manoochehri M. Tissue-specific down-regulation of the long non-coding RNAs PCAT18 and LINC01133 in gastric cancer development. Int J Mol Sci. 2018;19(12):3881.

45. Dou J, Tu D, Zhao H, Zhang X. LncRNA PCAT18/miR-301a/TP53INP1 axis is involved in gastric cancer cell viability, migration and invasion. J Biochem. 2020;168(5):547-55.

46. Yang XZ, Cheng TT, He QJ, Lei ZY, Chi J, Tang Z, et al. LINC01133 as ceRNA inhibits gastric cancer progression by sponging miR-106a-3p to regulate APC expression and the Wnt/ $\beta$-catenin pathway. Mol Cancer. 2018;17(1):126.

47. Iwakiri J, Terai G, Hamada M. Computational prediction of IncRNA-mRNA interactionsby integrating tissue specificity in human transcriptome. Biol Direct. 2017;12(1):15.

48. Liu X, Ma J, Xu F, Li L. TINCR suppresses proliferation and invasion through regulating miR-544a/FBXW7 axis in lung cancer. Biomed Pharmacother $=$ Biomedecine \& pharmacotherapie. 2018;99:9-17.

49. Guo F, Zhu X, Zhao Q, Huang Q. miR-589-3p sponged by the IncRNA TINCR inhibits the proliferation, migration and invasion and promotes the apoptosis of breast cancer cells by suppressing the Akt pathway via IGF1R. Int J Mol Med. 2020;46(3):989-1002.

50. Dong L, Ding H, Li Y, Xue D, Liu Y. LnCRNA TINCR is associated with clinical progression and serves as tumor suppressive role in prostate cancer. Cancer Manag Res. 2018;10:2799-807.

51. Hanahan D, Weinberg RA. Hallmarks of cancer: the next generation. Cell. 2011;144(5):646-74.

52. Tripathi V, Shen Z, Chakraborty A, Giri S, Freier SM, Wu X, et al. Long noncoding RNA MALAT1 controls cell cycle progression by regulating the expression of oncogenic transcription factor B-MYB. PLoS Genet. 2013;9(3): e1003368.

53. Xu F, Zha G, Wu Y, Cai W, Ao J. Overexpressing IncRNA SNHG16 inhibited HCC proliferation and chemoresistance by functionally sponging hsamiR-93. Onco Targets Ther. 2018;11:8855-63.

54. Ma YK, Shen TH, Yang XY. Upregulation of LncRNA FAM83H-AS1 in hepatocellular carcinoma promotes cell proliferation, migration and invasion by Wnt/ $\beta$-catenin pathway. Eur Rev Med Pharmacol Sci. 2019;23(18):7855-62.

55. Teng F, Zhang JX, Chang QM, Wu XB, Tang WG, Wang JF, et al. LncRNA MYLK-AS1 facilitates tumor progression and angiogenesis by targeting miR-424-5p/E2F7 axis and activating VEGFR-2 signaling pathway in hepatocellular carcinoma. J Exp Clin Cancer Res. 2020;39(1):235.

56. Jiang L, He Y, Shen G, Ni J, Xia Z, Liu H, et al. IncRNA HAND2-AS1 mediates the downregulation of ROCK2 in hepatocellular carcinoma and inhibits cancer cell proliferation, migration and invasion. Mol Med Rep. 2020:21(3):1304-9.
57. Bu WJ, Fang Z, Li WL, Wang X, Dong MJ, Tao QY, et al. LINC00240 sponges miR-4465 to promote proliferation, migration, and invasion of hepatocellular carcinoma cells via HGF/C-MET signaling pathway. Eur Rev Med Pharmacol Sci. 2020;24(20):10452-61.

58. Li Z, Zhang H. Reprogramming of glucose, fatty acid and amino acid metabolism for cancer progression. Cell Mol Life Sci. 2016;73(2):377-92.

59. Nakagawa H, Hayata Y, Kawamura S, Yamada T, Fujiwara N, Koike K. Lipid metabolic reprogramming in hepatocellular carcinoma. Cancers. 2018;10(11):447.

60. Tsai TH, Song E, Zhu R, Di Poto C, Wang M, Luo Y, et al. LC-MS/MS-based serum proteomics for identification of candidate biomarkers for hepatocellular carcinoma. Proteomics. 2015;15(13):2369-81.

61. Li L, Lei Q, Zhang S, Kong L, Qin B. Screening and identification of key biomarkers in hepatocellular carcinoma: evidence from bioinformatic analysis. Oncol Rep. 2017;38(5):2607-18.

62. Cannizzzaro R, De Re V, Simula M, Notarpietro A, de Zorzi M, Canzonieri V. Complement and coagulation cascades are involved in gastric cancer. 2011.

63. Rutkowski MJ, Sughrue ME, Kane AJ, Mills SA, Parsa AT. Cancer and the complement cascade. Mol Cancer Res. 2010;8(11):1453-65.

64. Xiao J, Zhang Y. Bioinformatics analysis for hepatocellular carcinoma genes based on the data of expression profile chip. Zhong Nan Da Xue Xue Bao Yi Xue Ban. 2020;45(9):1053-60.

65. Zeng H, Hui Y, Qin W, Chen P, Huang L, Zhong W, et al. High-throughput sequencing-based analysis of gene expression of hepatitis $B$ virus infection-associated human hepatocellular carcinoma. Oncol Lett. 2020;20(4):18.

66. Han J, Han ML, Xing H, Li ZL, Yuan DY, Wu H, et al. Tissue and serum metabolomic phenotyping for diagnosis and prognosis of hepatocellular carcinoma. Int J Cancer. 2020;146(6):1741-53.

67. Edling CE, Selvaggi F, Ghonaim R, Maffucci T, Falasca M. Caffeine and the analog CGS 15943 inhibit cancer cell growth by targeting the phosphoinositide 3-kinase/Akt pathway. Cancer Biol Ther. 2014;15(5):524-32.

68. Okano J, Nagahara T, Matsumoto K, Murawaki Y. Caffeine inhibits the proliferation of liver cancer cells and activates the MEK/ERK/EGFR signalling pathway. Basic Clin Pharmacol Toxicol. 2008;102(6):543-51.

\section{Publisher's Note}

Springer Nature remains neutral with regard to jurisdictional claims in published maps and institutional affiliations.

Ready to submit your research? Choose BMC and benefit from:

- fast, convenient online submission

- thorough peer review by experienced researchers in your field

- rapid publication on acceptance

- support for research data, including large and complex data types

- gold Open Access which fosters wider collaboration and increased citations

- maximum visibility for your research: over $100 \mathrm{M}$ website views per year

At BMC, research is always in progress.

Learn more biomedcentral.com/submissions 